Revue d'histoire de l'enfance « irrégulière » Le Temps de l'histoire

$4 \mid 2002$

Images de l'enfance et de la jeunesse « irrégulières »

\title{
De Delacroix à Poulbot, l'image du gamin de Paris
}

Jean-Jacques Yvorel

\section{(2) OpenEdition}

Journals

Édition électronique

URL : http://journals.openedition.org/rhei/52

DOI : $10.4000 /$ rhei.52

ISBN : 978-2-7535-1642-7

ISSN : $1777-540 \mathrm{X}$

Éditeur

Presses universitaires de Rennes

Édition imprimée

Date de publication : 15 novembre 2002

Pagination : 39-72

ISSN : 1287-2431

Référence électronique

Jean-Jacques Yvorel, « De Delacroix à Poulbot, l'image du gamin de Paris », Revue d'histoire de l'enfance « irrégulière » [En ligne], 4 | 2002, mis en ligne le 08 juin 2007, consulté le 03 décembre 2020. URL : http://journals.openedition.org/rhei/52 ; DOI : https://doi.org/10.4000/rhei.52

(c) PUR 


\section{De Delacroix à Poulbot, l'image du gamin de Paris}

Comme sa grande sœur la grisette, le gamin de Paris est l'un de ces types sociaux que le XIXème siècle, et plus précisément la Monarchie de Juillet, a construits. En général, ces "idéaux-types" sont des productions multimédiatiques à l'élaboration desquelles même la sociologie savante naissante contribue. Nous ne faisons pas là référence à d'actuels produits de haute technologie, mais à la façon dont s'élaborent ces archétypes : ils mobilisent presque toutes les formes de productions culturelles disponibles et suscitent entre elles un "dialogue", un jeu d'emprunts et de renvois que nous croyons pouvoir qualifier d'intermédiatique. Ainsi, notre gamin "se promène" dans les différentes formes de littérature pittoresque, dans le théâtre, dans la chanson, dans la poésie et, bien sûr, il se retrouve dans toutes sortes de représentations iconographiques : peintures, gravures, caricatures, estampes... Si, contrairement à la grisette, il n'est pas statufié, ${ }^{(2)}$ il est néanmoins sculpté par Étienne Marin Melingue. ${ }^{(3)}$ Mais, en plus, et c'est là un trait particulier de notre gamin, il connaît au mitan du siècle la consécration de la "grande littérature" : Victor Hugo va "créer un personnage là où il n'existait qu'un être collectif. Et ce personnage présente une particularité décisive : il est la voix des misérables ».() Le nom propre efface le nom commun, le mythe écrase l'archétype, Gavroche est désormais synonyme de gamin de Paris. Si, après la Commune de 1871, la silhouette du gamin s'estompe, ${ }^{(5)}$ elle ne disparaît pas complètement de la représentation symbolique de Paris. Gavroche et ses pairs survivent un temps au dernier grand soulèvement de la capitale. On utilise même sa notoriété à des fins publicitaires et la réclame s'empare de sa silhouette désormais bien reconnaissable. Ironie du sort, ce parangon de la liberté est le héros d'une série d'aventures à la gloire du colonialisme publiées
Jean-Jacques
Yvorel $^{(1)}$

(1) Historien, chargé

d'études au CNFE-PJJ,

Vaucresson.

(2) Nous pouvons contempler une statue dédiée À la grisette au carrefour de la rue du Faubourg-du-Temple et du boulevard Jules-Ferry.

(3) Il s'agit plus précisément d'un petit bronze de l'acteur Bouffé dans le rôle du "Gamin de Paris" dans la pièce éponyme de Bayard et Vanderbuch. Cette œuvre date de 1837 et est visible au Musée des arts décoratifs.

(4) Luce Abélès, "Le gamin de Paris", Cabiers-Musée d'art

Jean-Jacques Yvorel / p. 39 à 72 
et d'essai, 1985, p. 11.

Nous devons beaucoup à cette remarquable présentation.

(5) Frédéric

Chauvaud, "Gavroche et ses pairs : aspect de la violence politique $\mathrm{du}$ groupe enfantin en France au XIXème siècle”, Cultures \& conflits, n 18, été 1995 , p. 21-33. par Louis Boussenard dans le Journal des voyages, sous le titre générique Le tour du monde d'un gamin de Paris. Plus fondamentalement, le gamin de Paris se transforme en "gosses des rues". Des écrivains à tendance populiste comme Léon Frapié, des illustrateurs comme Steinlen, Naudin ou bien sûr Poulbot, nous décrivent un enfant pauvre de "la butte" ou "des fortifs", confronté à un quotidien difficile. Assurément, le gosse de la Belle Epoque a perdu une part de la liberté de son ancêtre de la Monarchie de Juillet : le maître d'école, la famille, le concierge, le policier, le voisin, le boucher, en un mot les adultes surveillent ses jeux, ce qui est aussi la marque d'une prise de conscience des devoirs de la société à l'égard de l'enfance populaire.

Nous avons essayé de suivre "en images", la naissance, les évolutions, les diverses facettes de notre type social. Il nous faudra bien évidemment mettre en relation ces images avec d'autres représentations du "gamin de Paris", car elles ne sont pas compréhensibles en dehors du lien intermédiatique.

\section{I. "L'Enfant aux pistolets" ou la première apparition du "gamin de Paris"?}

\section{I.1 Le tableau de Delacroix}

La Liberté guidant le peuple, d'Eugène Delacroix, est un tableau plus que célèbre et probablement le plus reproduit de notre pays. Cette huile polychrome sur toile de grandes dimensions, $2 \mathrm{~m} 60$ sur $3 \mathrm{~m} 25$, est peinte entre septembre et décembre 1830. Elle est présentée au Salon de 1831, entre le 1er mai et le 15 août. Le peintre lui a donné pour titre Le 28 juillet et pour sous-titre la Liberté guidant le peuple. Seul le sous-titre est passé à la postérité. [Cf. figure 1]

Deux enfants figurent sur le tableau. Celui de gauche est coiffé du bonnet des voltigeurs de la Garde nationale, cette milice civique bourgeoise dissoute par Charles-X après une revue de troupe mouvementée, en avril 1827, où le roi est accueilli aux cris de Vive la réforme. L'enfant de droite, la faluche des étudiants en guise de couvre-chef et brandissant deux pistolets, est plus remarquable. 


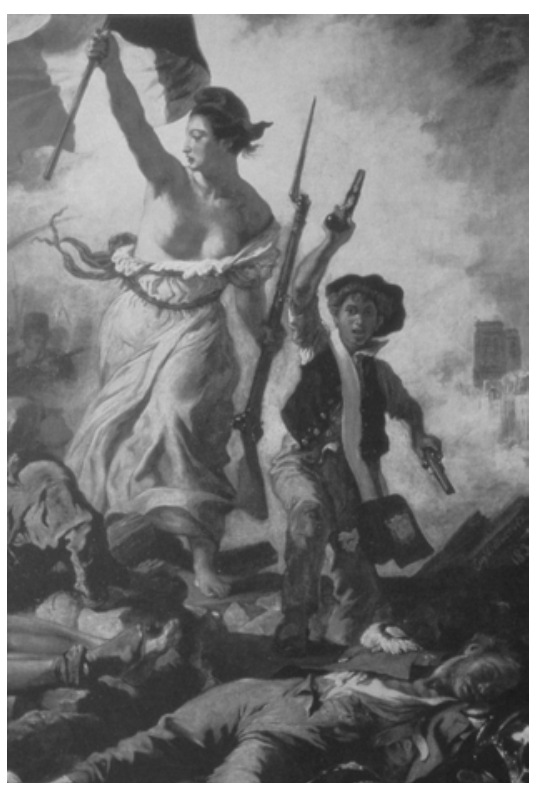

Fig. 1

Eugène Delacroix,

La liberté

guidant le peuple.

L'enfant aux

pistolets (détail).

Musée du Louvre,

cliché Michel

Basdevant.

La plupart des commentateurs en ont fait le prototype du gamin de Paris. En effet, Eugène Delacroix représente là un enfant du peuple (malgré sa coiffure, il ne peut s'agir d'un étudiant), participant à une insurrection urbaine symbolisée par une barricade, même si elle est peu élevée. Or, l'extraction populaire et l'appétence pour les barricades sont deux caractéristiques attribuées au gamin de Paris.

\section{I.2 Un thème largement traité}

Cependant, Delacroix n'est pas le seul à immortaliser par l'image les Trois Glorieuses et, si la facture esthétique de son tableau lui donne une place singulière et importante dans l'histoire de l'art, les éléments que le peintre fait entrer dans sa composition se retrouvent dans bien d'autres représentations. Rappelons que, dans l'euphorie qui suit la chute de Charles-X, les propos comme les images exaltent cette union de toutes les classes de la société qui a permis l'avènement du "règne de la liberté". Pas une gravure, pas un tableau des événements de juillet qui ne s'ef- 
(6) Voir, par exemple,

Le 28 juillet, défense

d'une barricade, gravure

“à la manière noire”

de Marriner, BN,

Estampe, ou le tableau d'Hippolyte Lecomte,

Combat de la rue

de Rohan, musée

Carnavalet.

(7) Souligné par

l'auteur.

(8) A. de Sainte, Les enfans de Paris ou les petits patriotes, scènes de courage, de présence d'esprit, de magnanimité, de grandeur d'âme et de désintéressement de la jeunesse parisienne pendant les journées des 27, 28, 29 juillet 1830, Paris, Nepveu, 1831, p. 10. forcent de faire figurer tous les types sociaux parmi les insurgés. Le couvre-chef sert alors bien souvent de marqueur et le haut-de-forme du bourgeois se mêle à la casquette de l'ouvrier, le tricorne du polytechnicien au bonnet du garde national, la faluche de l'étudiant au schako de quelques vieux soldats de l'Empire. Les commentaires qui accompagnent souvent les gravures détaillent même parfois les diverses coiffes et leur signification symbolique. ${ }^{(6)}$

Dans ce concert unanimiste, la participation des fils au combat des pères est glorifiée et vue comme le gage de la régénération. Alexis Eymery, par exemple, publie sous le pseudonyme de A. de Sainte un ensemble de douze histoires édifiantes, illustrées par autant de vignettes et mettant en scène des enfants et des adolescents. Dans l'introduction de son ouvrage, il écrit :

"Quoique la jeunesse ne doive s'occuper que d'études, quoique ses devoirs ne lui permettent pas de s'immiscer dans la politique, qui est du domaine de l'âge mûr, cependant l'empire impérieux des circonstances en a décidé autrement pendant les 27,28 et 29 juillet ; c'est la jeunesse qui a presque tout fait. On a vu des enfans de Paris, ${ }^{(7)} \mathrm{dont}$ la plupart étaient de jeunes ouvriers, des étudians, des apprentis, que quelques citoyens plus âgés dirigeaient parfois, donner l'impulsion et amener ce beau mouvement qui, s'emparant, en définitive, de toutes les classes de la société, a déterminé ce changement heureux dans nos institutions qui doit assurer pour toujours le bonheur des Français et des peuples qui les imiteront. ${ }^{\left({ }^{(8)}\right.}$

Le frontispice de ce livre est formé par la vignette qui illustre la première scène de l'ouvrage, intitulée Les Barricades. Le jeune Apprenti imprimeur. [Cf. figure 2]

Une légende nous apprend que le personnage qui va planter un drapeau tricolore au milieu de cette barricade construite au Carré SaintMartin est un apprenti imprimeur et que l'enfant de six ans qui porte des cartouches aux combattants dans son tablier d'écolier est son petit frère. L'histoire précise que ce héros de Juillet, nommé Ernest Dutocq, avide de savoirs, est désormais patronné par une personne de qualité. Il étudie 


\section{LE JEUNE APPTENTI LMPRIMEUR.}

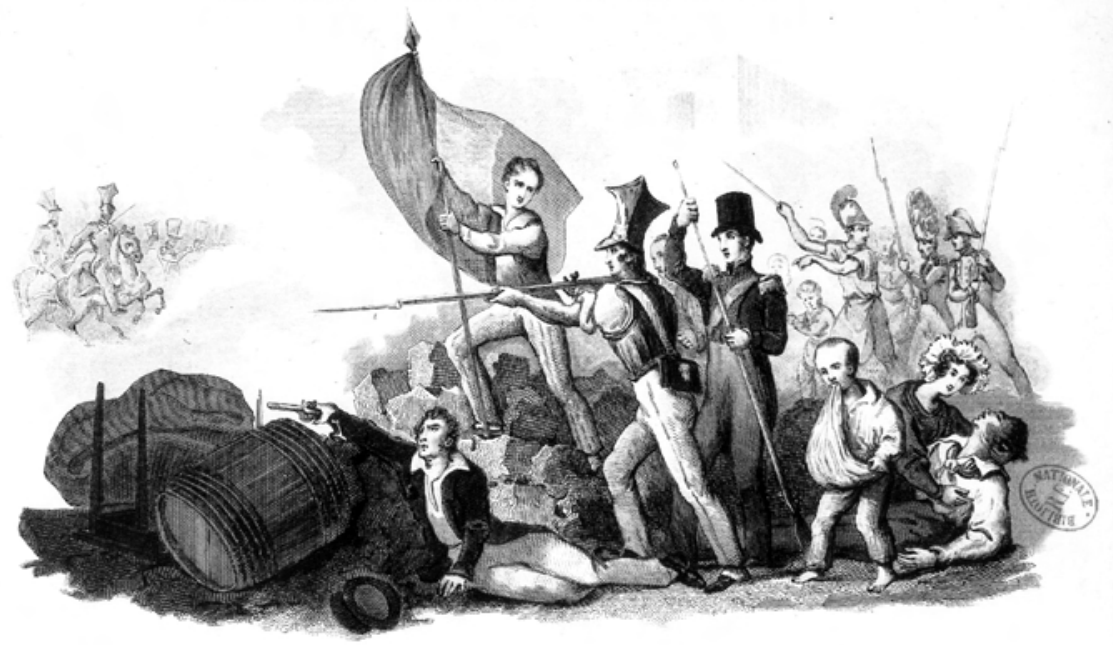

Ies amis! defendons ee signe'? e'est eelui de tons les firançais et de la Vietoire

Fig. 2

A. de Sainte, Les enfans de Paris ou

les petits patriotes (frontispice),

Paris, Nepveu, 1831.

Cliché Bibliothèque nationale de France.

les mathématiques et prépare son entrée à Polytechnique. Tous les autres enfants et adolescents dont l'auteur nous conte l'histoire ont des vies aussi exemplaires que celle du jeune Ernest.

Il consacre bien évidemment un chapitre à l'histoire du jeune Arcole. Arcole, dont « le souvenir demeurait chargé de valeurs révolutionnaires à la fin du Second Empire ", ${ }^{(9)}$ est un jeune garçon qui, durant les combats pour la conquête de l'Hôtel de Ville, se serait élancé sur la passerelle de Grève afin de planter un drapeau tricolore. La scène a été immortalisée par ailleurs dans plusieurs œuvres picturales. ${ }^{(10)}$ C'est lors du remplacement du vieil édifice par une construction en pierre, en

(9) Jean Maitron, [dir.], Dictionnaire biographique du mouvement ouvrier français, Paris, Éditions ouvrières, 1964, tome 1. A. de Sainte fait d'Arcole un apprenti serrurier.

(10) La scène du pont de Grève a notamment été peinte par M.A. Bourgeois, Prise de l'Hôtel de Ville, Musée de Versailles, MV. 5186. 


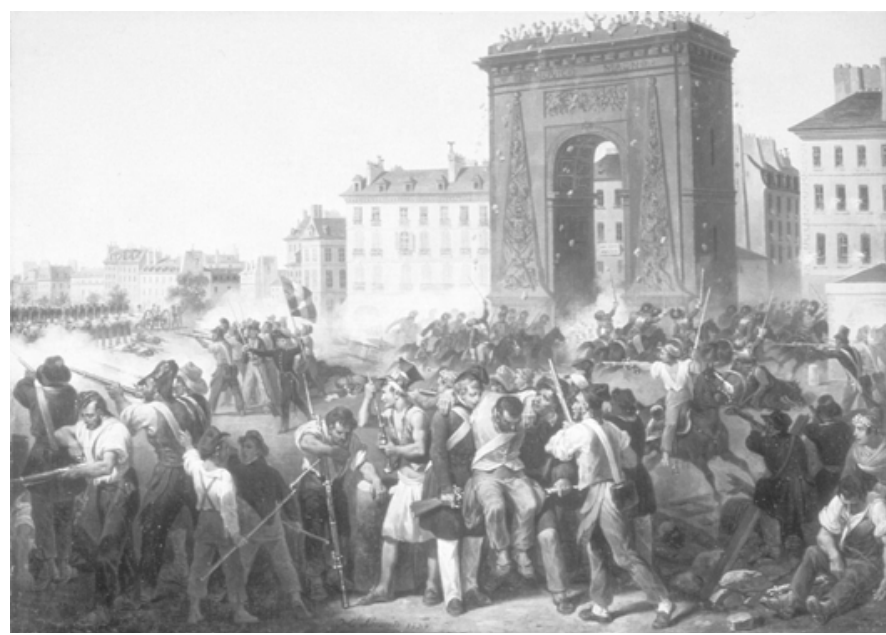

1855, que le pont prendra le nom d'Arcole. En fait, il semble que le jeune héros se nommait Jean Fournier.

Dans le tableau qu'Hippolyte Lecomte consacre à l'un des épisodes des Trois Glorieuses, les combats de la porte Saint-Denis, ${ }^{(11)}$ deux enfants, dont l'un porte un fusil, sont visibles au premier plan. [Cf. figure 3]

p. 214.

(12) Cité par Luce

Abélès, art. cit., p. 11.

(13) Sur ce peintre,

voir Madeleine Rous-

seau, La vie et l'auvre de

Philippe-Auguste Jeanron,

Paris, Réunion des

Musée nationaux, 2000, $356 \mathrm{p}$.

(14) Luce Abélès, art. cit., p. 9.
Fig. 3

Hippolyte Lecomte, Combats de la porte Saint-Denis. Musée Carnavalet, PMVP, cliché Toumazet.
"L'enfant aux pistolets" est même présent dans le texte qui accompagne la lithographie que Jazet a tirée de cette œuvre :

"Lors de l'affaire de la porte Saint-Denis, un enfant de quinze ans s'est avancé au milieu des feux de la mitraille et de mousqueterie jusqu'auprès d'un des officiers commandant la cavalerie [...] et d'un coup de pistolet il lui a cassé la tête. » ${ }^{(12)}$

Dans le tableau de Philippe Auguste Jeanron, ${ }^{(13)}$ Les petits patriotes [ $c f$. figure 4], même si sa facture est très différente, nous retrouvons des éléments de la composition de Delacroix : la barricade, les armes, les chapeaux (ici un tricorne de polytechnicien et un schako de lancier). La tranquillité de ces jeunes combattants, qui se reposent alors que l'échauffourée se poursuit au loin (l'un d'entre eux est même endormi), symbolise allégoriquement « le triomphe paisible du peuple sûr de son bon droit ».(14) 


\section{I.3 Entre Bara et Gavroche}

Tous ces tableaux, toutes ces gravures empruntent au mythe des enfants héros de la Révolution, notamment aux représentations des épopées de Bara et Viala. Une des vignettes du livre de A. de Sainte représente le jeune Émilien, "fils d'un pauvre perruquier ", mourant sous les coups de sabres des cavaliers du maréchal Marmont, ${ }^{(15)}$ en " tenant son drapeau et en s'écriant je mœurs pour la patrie! " C'est en criant "Vive la République" que Bara tombe sous les coups des Vendéens et David le peindra serrant une cocarde tricolore. ${ }^{(16)}$ Le petit tambour est un bon fils, qui «se bornant aux dépenses d'une absolue nécessité a fait passer à sa famille nombreuse et indigente tout ce qu'il pouvait économiser ", précise la légende d'une estampe de l'an-II. ${ }^{(17)}$ Nous trouvons les mêmes vertus chez les enfants héros de 1830, que ce soit chez $\mathrm{A}$. de Sainte ${ }^{(18)}$ ou chez le Baron de La Mothe-Langon, auteur d'un roman dont le héros, Fanfan bonnet bleu, est un apprenti titulaire de la Croix de Juillet. ${ }^{(19)}$ L'association d'un enfant combattant et de la Liberté sym-

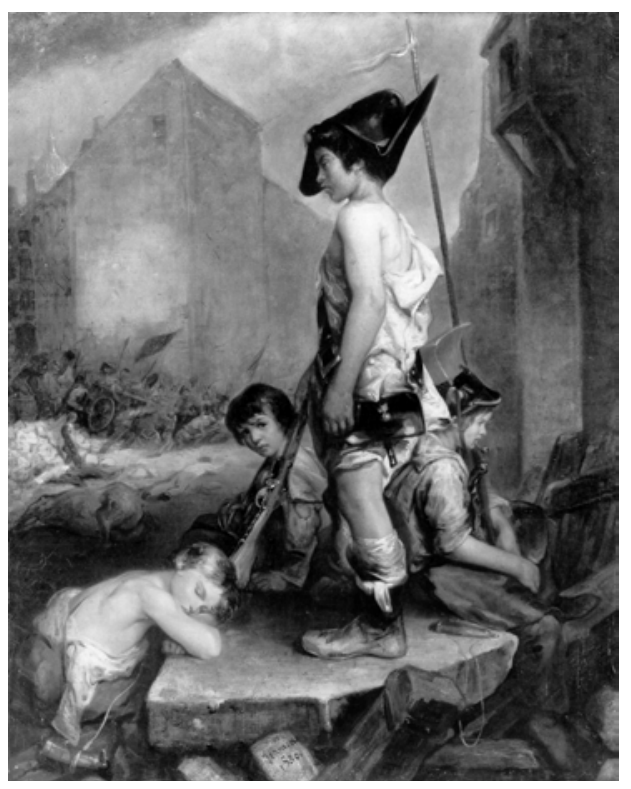

Fig. 4

Philippe Auguste

Jeanron,

Les petits patriotes.

Musée des

Beaux-Arts de

Caen,

cliché M. Seyve.

(15) Le maréchal

Marmont, duc de

Raguse, major général de la Garde royale, s'est vu confier par Charles-X la répression du soulèvement.

(16) Jacques-Louis David, La mort de Bara, musée Calvet, Avignon.

(17) Mort de Bara dédiée aux jeunes Français. Dessiné et peint par P. L. Debucourt, an II., $\mathrm{BN}$, Estampe, collection Hennin.

(18) L'apprenti serrurier Arcole donnait scrupuleusement à sa mère les 5 francs que son patron lui remettait chaque semaine.

(19) Étienne-Léon de la Mothe-Langon, Le gamin de Paris, histoire contemporaine, Paris, C. Lachappelle, 1833, 5 vol. 
(20) Bara couronné par la Liberté, gravure à l'aquatinte de Boissier, $\mathrm{BN}$, Estampe, collection de Vinck.

(21) « Le petit tambour Darruder combattait aux côtés de son père, quand ce dernier fut tué $[. .$.$] ; s'emparant$ $\mathrm{du}$ pistolet de son père, il tua le meurtrier et continua à battre la charge ". Raymonde Monnier, "Le culte de Bara en l'an-II", dans Joseph Bara (1779-1793).

Pour le deuxième centenaire de sa naissance, Paris,

Ville de Palaiseau,

Société des études robespierristes, 1981, p. 51.

(22) Jean-Alphonse Rœhn, Inbumation des victimes de juillet devant la colonnade du Louvre, musée Carnavalet.

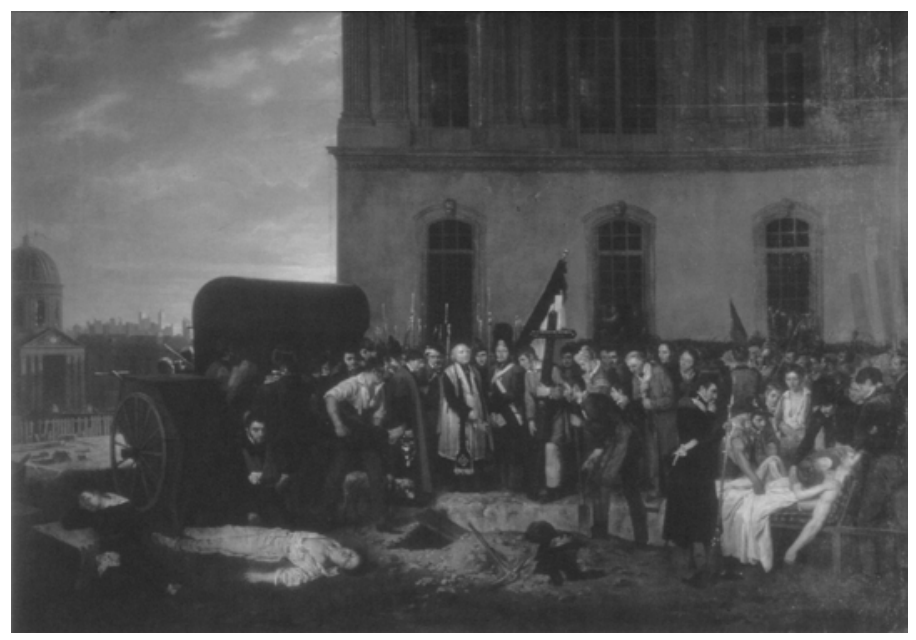

Fig. 5 Jean-Alphonse Roehn, Inbumation des victimes de juillet devant la colonnade du Louvre. Musée Carnavalet, PMVP, cliché Ph. Joffre.

bolisée par une femme au sein nu et coiffée d'un bonnet phrygien n'est pas l'apanage du peintre si bien chanté par Baudelaire. Nous la retrouvons également dans l'iconographie révolutionnaire. ${ }^{(20)}$

Par leur extraction fréquemment populaire et leur rôle dans le soulèvement insurrectionnel, les enfants de 1830 sont proches du gamin de Paris, mais, par bien d'autres traits, ils s'en éloignent fortement. Présentés comme d'honnêtes travailleurs et des fils respectueux qui luttent aux côtés de leurs pères, comme Darruder le petit tambour de l'an-II, ${ }^{(21)}$ ils n'ont rien d'enfants des rues plus ou moins délaissés par des familles auxquelles, de leur côté, ils chercheraient à échapper. Le tableau de JeanAlphonse Rohn, l'Inbumation des victimes de juillet devant la colonnade du Louvre, ${ }^{(22)}$ en témoigne. [Cf. figure 5]

Il peint deux familles frappées par les événements. À droite, un jeune combattant mort - dont le corps d'éphèbe nous fait penser au Bara de David - est pleuré par une femme et un homme en redingote et chapeau haut-de-forme qui a participé à la lutte, comme le prouve son bras en écharpe. À gauche, deux enfants à la mise "prolétarienne" contemplent tristement un homme mort qu'une femme éplorée enlace. 
Les jeunes émeutiers ont un langage toujours "politiquement correct" et très éloigné de la gouaille de Gavroche et de ses pairs. Ils ne meurent pas le lazzi à la bouche, mais se contentent de crier "Vive la charte, Vive la patrie" ou d'entonner des chants patriotiques.

Il nous semble que le corpus iconographique "juvénile” de 1830 peut être vu comme un ensemble d'images intermédiaires. En effet, nous retrouvons dans ces représentations certains caractères de l'enfant-soldat héros de la Grande Révolution, mais aussi quelques traits de l'enfantémeutier des révolutions perdues du XIXème siècle, à commencer par un statut de civil. "L'enfant aux pistolets" n'est plus vraiment le petit frère de Bara, il n'est pas encore tout à fait le grand frère de Gavroche.

\section{La construction d'un archétype ambigu et ses représentations iconographiques}

Dès 1831, la quasi-unanimité faite autour de l'enfant des barricades se fissure, alors que parallèlement la silhouette du gamin de Paris se précise.

\section{II.1 L'enfant émeutier : un héros contesté}

La participation des enfants et des adolescents aux événements de Juillet n'est guère péjorée que par quelques légitimistes. Ainsi Chateaubriand qui, dans ses Mémoires d'outre-tombe, porte un regard très négatif non seulement sur le rôle joué par la progéniture des classes populaires durant les Trois Glorieuses, mais sur leur personnalité :

«Les enfants, intrépides parce qu'ils ignorent le danger, ont joué un triste rôle dans les trois journées : à l'abri de leur faiblesse, ils tiraient à bout portant sur les officiers qui se seraient crus déshonorés en les repoussant. Les armes modernes mettent la mort à la disposition de la main la plus débile. Singes laids et étiolés, libertins avant d'avoir le pouvoir de l'être, cruels et pervers, ces petits héros des trois journées se livraient à des assassinats avec tout l'abandon de l'innocence. " ${ }^{(23)}$ Cette opinion, minoritaire au lendemain des Trois Glorieuses, se renforce considérablement alors que les insurrections républicaines et les soulèvements ouvriers se multiplient. En février 1831, un service religieux à la mémoire du duc de Berry provoque une émeute et le saccage
(23) François René de

Chateaubriand,

Mémoires d'outre-tombe,

(1841), rééd. Paris,

Gallimard, 1951,

tome II, p. 430, cité par Jean-Pierre A. Bernart, Les deux Paris. Les représentations de Paris dans la seconde moitié du XIXème siècle, Paris, Champ Vallon, 2001, p. 254. 
(24) Pour Lyon, voir par exemple les témoignages de Jean-Baptiste Montfacon ou d'Eugène Baune, cités par Fernand Rude, La révolte des canuts 1831-1834, Paris, François Maspéro, 1982, p. 41 ; ou celui d'Aimable Guillon, cité par Maurice

Moissonnier, Les canuts, Paris, Messidor/Éditions sociales, 1988, p. 188. Pour Paris, voir entre autres Alexandre Dumas, Mes mémoires (18311833), rééd. Paris, Robert Laffont, 1989, p. 835 ; ou Mémoires de Canler, ancien chef de sûreté, édition présentée et annotée par Jacques Brenner, Paris, Mercure de France, 1968, p. 105106. Mais on pourrait citer bien d'autres textes.

(25) Voir, par exemple, le personnage de Joseph dans Antoine-FrançoisMarius Rey-Dussueil, Le cloître Saint-Merry, Paris, A. Dupont, 1832, 405 p. de l'église de Saint-Germain-l'Auxerrois. En novembre de la même année, les canuts lyonnais se soulèvent. À Paris, les républicains prennent les armes contre le régime de Louis-Philippe en juin 1832. Ces mouvements ressurgissent dans ces deux grands bastions du républicanisme et du socialisme en avril 1834. Tous les témoignages concordent pour relever à chaque fois la participation des enfants aux combats. ${ }^{(24)} \mathrm{Si}$ les républicains et les démocrates continuent de voir en eux des petits héros, ${ }^{(25)}$ pour les défenseurs de l'ordre instauré par "l'aristocratie des écus", ils deviennent des "pousse à l'émeute" et de la graine de violence. Canler, ancien chef de sûreté, raconte dans ses mémoires un épisode des émeutes de 1832 qui suivent l'enterrement du général Lamarque. Un geste, bien proche de l'épisode de la porte Saint-Denis, considéré dans le contexte de 1830 comme héroïque, est réévalué dans le sens que lui donnait Chateaubriand :

«Un gamin d'une douzaine d'années, vêtu d'une veste couleur auvergnate, s'était, bon gré mal gré, faufilé au premier rang.

Tout le monde connait cette race du gamin de Paris, qui dans nos rassemblements a toujours poussé le premier cri séditieux, dans nos émeutes a porté le premier pavé à la première barricade, et qui presque toujours a tiré le premier coup de feu.

Le mauvais garnement avait à la main un pistolet d'arçon presque aussi long que son bras, et, au moment où le commandant Chollet commençait à adresser aux individus qui l'entouraient quelques paroles qui vraisemblablement auraient désarmé leur colère, l'infernal gamin avait pressé la détente de son pistolet et avait disparu aussitôt, avant même qu'on se fût aperçu du déplorable résultat de son action. " ${ }^{(26)}$

Que l'action politico-insurrectionnelle des enfants soit évaluée favorablement ou pas, elle est désormais l'œuvre des gamins. Rey-Dussueil, traducteur d'un des livres-phares du risorgimento italien, Les fiancées, d'Alessandro Manzoni, consacre un roman à l'insurrection républicaine de 1832. Joseph, fils d'ouvrier, meurt en résistant jusqu'au bout aux assauts des forces royales. Cet enfant «à l'air mutin et tendre » est, nous dit l'auteur, « le vrai type de ce qu'on est convenu d'appeler le gamin de Paris, enfants qui promettent à la France une génération de héros, bercés 
au bruit des gloires de l'Empire, nourris dans l'amour de la liberté et dans le mépris de la vie. Ils vont aux combats comme jadis, à leur âge, on allait au jeu. " ${ }^{(27)}$ Joseph est le vrai ancêtre de Gavroche... Moins de deux ans après la chute du régime de Charles-X, l'enfant-émeutier ne peut appartenir qu'à "la race des gamins de Paris" et, réciproquement, derrière chaque gamin sommeille un émeutier. De la rue Transnonain (28) à la Commune, il n'y a guère d'images de barricades d'où sa silhouette soit absente. La vision développée par les artistes à l'égard de cet enfant dépendra aussi de leur opinion face aux mouvements insurrectionnels du XIXème siècle et, plus globalement, de la manière dont ils appréhendent le peuple. Le gamin sera représenté tantôt comme un "singe étiolé et laid [...] cruel et pervers ", tantôt comme un héros " mutin et tendre ".

\section{2 La construction de l'archétype}

La construction de l'archétype du "gamin de Paris" mobilise, nous l'avons dit, dans les années 1830-1840, toutes les formes de littérature. Les tableaux de Paris, genre inauguré au XVIIIème siècle par LouisSébastien Mercier, comme les fresques dédiées à la France pittoresque, réservent désormais un chapitre à cet enfant un peu particulier de la capitale. Les physiologies ${ }^{(29)}$ ne pouvaient pas éviter ce type et le théâtre se devait de lui consacrer quelques pièces. La chanson et la poésie ne sauraient l'ignorer. Les diaristes et autres auteurs de mémoires, s'ils ne sont pas strictement provinciaux, le croisent nécessairement. Les romanciers en font un personnage au moins secondaire de leurs intrigues. Il ne s'agit pas ici d'analyser, même succinctement, cette masse d'imprimés à plus ou moins grand tirage, mais de voir comment ces textes sont, directement ou indirectement, illustrés au sens premier du terme.

Les arts graphiques, comme la littérature, représentent le gamin sous un jour plus ou moins favorable. Cependant, au-delà des contrastes, nous trouvons un socle commun sans lequel l'archétype n'existerait pas. Le gamin, qu'on le vilipende ou qu'on l'encense, conserve toujours certaines caractéristiques que les artistes s'efforcent de souligner dans leurs dessins ou tableaux.

(26) Mémoires de Canler, ancien chef de sûreté, op. cit., p. 105-106.

(27) Antoine-FrançoisMarius Rey-Dussueil, op. cit., p. 72-73, cité par Luce Abélès, art. cit., p. 9.

(28) Célèbre épisode des révoltes de 1834 immortalisé par Honoré Daumier.

(29) Sur ce genre littéraire, voir Richard Sieburth, "Une idéologie du lisible : le phénomène des Physiologies", Romantisme, 1985, n 47, p. 39-60. 
(30) Pont d'Arcole, le 28 juillet 1830, Eau forte burin et pointillé, Musée Carnavalet.

(31) Goblain,

Hôtel de Ville (Pont d'Arcole), Estampe, Musée Carnavalet.

\section{II.2.1 Le gamin : un enfant du peuple}

S'il peut y avoir doute sur l'identité sociale de l'enfant de 1830, si, selon les sources, le jeune Arcole est étudiant comme sur une gravure anonyme conservée au musée Carnavalet ${ }^{\left({ }^{(3)}\right.}$ ou ouvrier comme sur une gravure de Goblain, ${ }^{(31)}$ il n'y a pas d'hésitation sur l'origine populaire du gamin.

\section{DEUX REPRÉSENTATIONS DU JEUNE ARCOLE : FILS DE}

\section{LA BOURGEOISIE OU "FILS DU PEUPLE" ?}
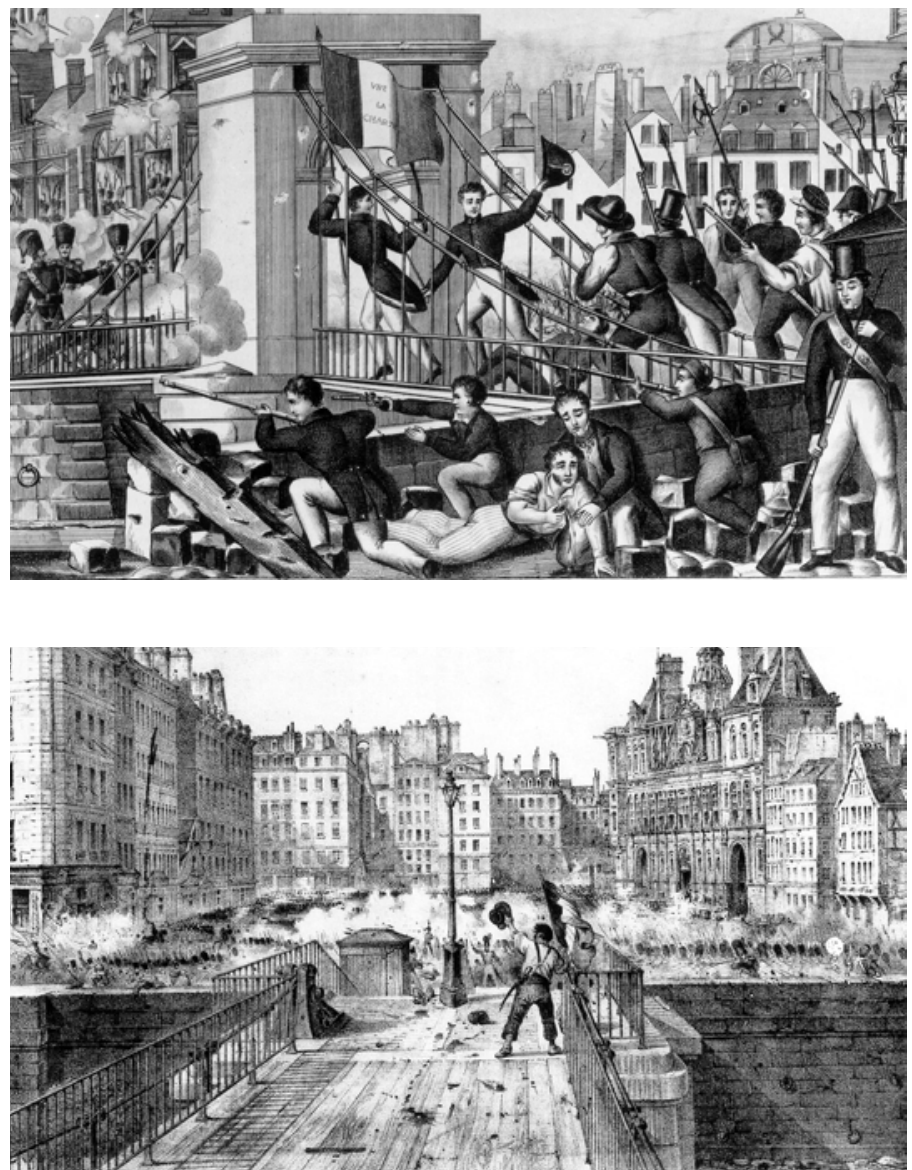

Fig. 6

Anonyme, Pont d'Arcole, le 28 juillet 1830. Musée Carnavalet, estampe, PMVP, cliché R. Briant.

Fig. 7

Goblain, Hôtel de Ville (Pont d'Arcole). Musée Carnavalet, estampe, PMVP, cliché inconnu. 
Les auteurs qui partagent la vision positive de Georges d'Outremont en font un apprenti : "Le gamin a de dix à quinze ans ; fils d'ouvrier, il est apprenti... " (32) ; un apprenti peu discipliné qui, "oubliant tout à fait la commission dont il est chargé, vague dans les rues, flâne aux devantures des boutiques, fait la grimace aux marchandes, des niches aux passants, aigrit le caractère des chiens et parcourt gaiement la capitale assis sur le marchepied des voitures $»{ }^{(33)}$ Quand la légende noire l'emporte, il devient un enfant naturel, né dans une mansarde, engendré par le vice, l'alcoolisme, l'irréligion et la misère. ${ }^{(34)}$

Pour traduire cette extraction plébéienne, peintres, dessinateurs ou caricaturistes utilisent le vêtement qui, au XIXème siècle, dit beaucoup de l'appartenance de classe. Nous pourrions penser que tous les artistes qui ont peint, gravé ou dessiné un gamin ont lu Paris ou le livre des centet-un, tant nous retrouvons sous leurs pinceaux, leurs burins ou leurs plumes la description de Georges d'Outremont :

«Et puis le gamin n'a pas de costume attitré ; il porte tantôt le tablier vert, ou la blouse noircie par le fer ; tantôt un bonnet de papier, une chétive casquette, une calotte à la grecque. Pour des bas, c'est du luxe ; pas de mouchoir de poche, à quoi bon ; quelques lambeaux de chemise passent à travers son pantalon troué, et complètent son costume. Il faut que ses vêtements soient percés, ou du moins qu'ils aient des pièces non assorties. " ${ }^{(35)}$

Le tableau d'Ernest-Louis Pichio, ${ }^{(36)}$ avec son petit coursier qui a encore sa hotte sur le dos et l'enfant qui, au premier plan, ramasse un fusil, fournit un bon exemple de représentation de la vêture du gamin, mais c'est tout notre corpus qui aurait pu être appelé pour illustrer notre propos. [Cf. figure 8]

\section{II.2.2 Le gamin : un amateur de spectacles, joueur, frondeur et moqueur}

Le gamin a un "goût immodéré pour les spectacles du boulevard, sans parler de ceux de la rue, où il forme toujours le premier noyau du cercle. [...] Il est l'ami et le public de tous les plaisirs gratuits, et vous le trouverez tour à tour au spectacle de la morgue, à celui de Guignol, dans le cercle d'un chanteur ou d'un équilibriste en plein vent. On connaît
(32) Georges

d'Outremont, "Le gamin de Paris", dans Paris ou le livre des cent-et-un, Paris, 1832, p. 125.

(33) Louis Huart, Physiologies du flâneur, Paris, Lavigne, 1841, p. 69.

(34) Ernest Bourget, Physiologie du gamin de Paris. Galopin industriel, Paris, J. Laisné, 1842, (chapitre 2,

"Naissance du gamin").

(35) Georges d'Outremont, op. cit., p. 126-127.

(36) Ernest-Louis Pichio, Alphonse Baudin sur la barricade, musée Carnavalet. 
(37) Victor Fournel, Ce qu'on voit dans les rues de Paris, Paris, Dentu, 1867, p. 350.

(38) Henri Monnier, Scènes populaires dessinées à la plume, Paris, Canel, 1831, p. 97-110.

(39) M.-A. Bazin,

L'époque sans nom, esquisses de Paris 18301833, Paris, A. Mesnier, 1833, cité par Luce Abélès, art. cit., p. 2.

(40) Vignette en couleur du livre d'Henry Monnier, op. cit., p. 96.

(41) Voir par exemple Jean Pezous, La descente de la Courtille, musée Carnavalet.

(42) Le bouchon est un jeu dans lequel on met des pièces de monnaie sur un bouchon qu'il s'agit d'abattre avec un palet (Émile Littré).

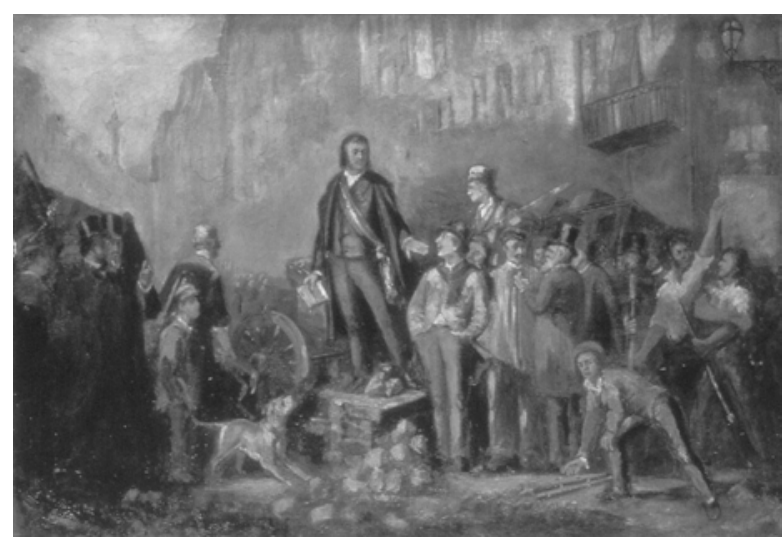

Fig. 8

Ernest-Louis Pichio, Alphonse Baudin sur la barricade. Musée Carnavalet, PMPV, cliché R. Briant.

son fanatisme pour certaines pièces et pour certains acteurs des théâtres populaires ", écrit Victor Fournel en 1867.(37) L'auteur de Ce qu'on voit dans les rues de Paris reprend là un trait de caractère bien établi. Déjà en 1831, dans ses Scènes populaires, Henri Monnier raconte les efforts de Titi et Lolo pour assister à une exécution capitale ${ }^{(38)}$ et M.-A. Bazin, dans ses Esquisses de Paris, note, tout comme Georges d'Outremont, cette aptitude à être " toujours le premier là où il y a quelque chose à voir ". ${ }^{(39)}$ Aussi, quand il n'est pas représenté comme soldat de quelque révolution plus souvent perdue que victorieuse, le gamin est au poulailler d'un théâtre, comme sur une lithographie de Provost, au premier rang d'un attroupement écoutant un bonimenteur, perché sur un lampadaire pour voir passer une revue ou mieux observer la guillotine ${ }^{(40)}$ et, bien sûr, dans la foule en liesse d'un quelconque carnaval. ${ }^{(41)}$

"Encore un an de bouchon ${ }^{(42)}$ et ce sera fini ", promet Joseph, le gamin de Paris de la pièce éponyme de Bayard et Vanderbuch. Ces auteurs de pièces de boulevard soulignent là un trait de caractère maintes fois relevé : « Le gamin est joueur, mais joueur dans l'âme, joueur avec frénésie. [...] C'est avec passion qu'il joue des gros sous ; vous jouez de l'or : voilà la différence. Le jeu national du gamin, c'est le bouchon. " ${ }^{(43)}$ Frégier en fait une cause importante de la déviance juvénile des enfants des classes laborieuses ; "il était joueur, il devient vagabond ", écrit-il, avant de 
décrire la façon dont le vagabondage conduit à la délinquance. ${ }^{(4)}$

Face au canon, au théâtre ou dans la rue, le gamin braille, raille, gouaille. Si tous les textes qui lui sont consacrés, avant ou après Victor Hugo, s'arrêtent sur son langage et soulignent sa tendance à se moquer de ses contemporains, surtout ceux qui, de près ou de loin, ont à voir avec l'autorité, il est plus difficile de traduire par l'image la faconde de nos titis ${ }^{(4)}$ parisiens. Le côté frondeur du personnage est cependant bien rendu par Daumier [cf.figure 9] : pour illustrer les journées de février 1848, il juche sur le trône de Louis-Philippe un ancêtre de Gavroche à l'air goguenard. ${ }^{(46)}$

\section{II.2.3 Le gamin : un vagabond parisien}

Le gamin vague, vaque, erre, flâne, muse, se promène. Cette propension à parcourir le pavé parisien, parfois considérée avec sympathie, devient le plus souvent la matrice de toutes les déviances qui, plus ou moins brutalement, transforment le gamin en "pâle voyou". Sur ce

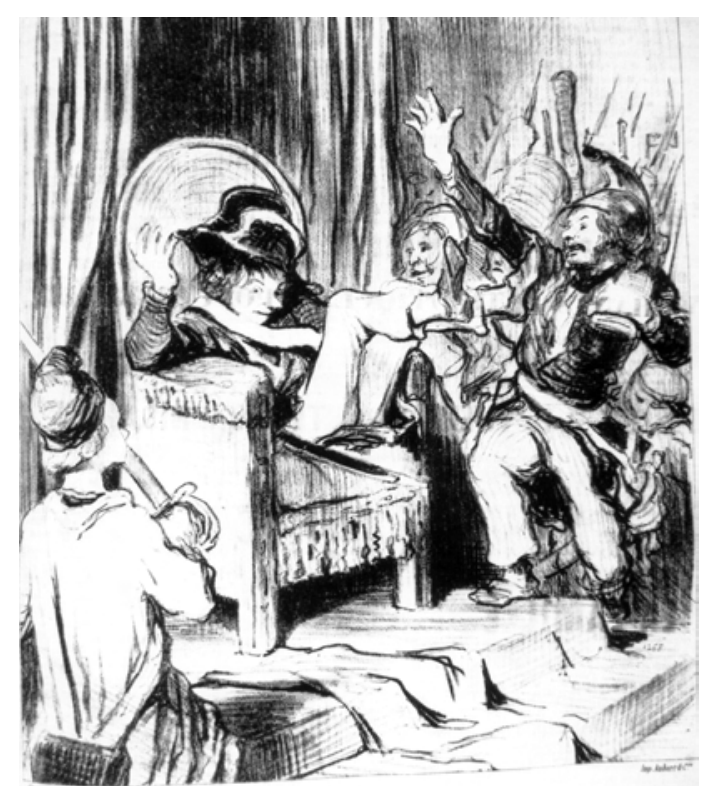

Fig. 9

Honoré Daumier, Le Charivari, 4 mars 1848. BHVP, cliché M. Basdevant.
(43) Georges d'Outremont, op. cit., p. 133.

(44) H.-A. Frégier, Des classes dangereuses de la population des grandes villes et des moyens de les rendre meilleures, Paris, 1840, vol. 2, p. 69-73.

(45) Titi est utilisé comme nom propre dès 1830 et comme substantif synonyme de gamin dans les années 1860, notamment par Victor Fournel, op. cit., p. 351.

(46) Honoré Daumier, "Le gamin de Paris aux Tuileries", Le Charivari, 4 mars 1848 
(47) Société pour le patronage des jeunes libérés du département de la Seine, Assemblée du 18 mars 1834, rapport du président Alphonse Bérenger (de la Drôme), p. 12-13.

(48) H.-A. Frégier, op. cit., Paris, 1840 , vol. 1, p. 195-200.

(49) Dominique Kalifa, L'encre et le sang, Paris, Fayard, 1995, 350 p.

(50) Louis Chevalier, Classes laborieuses, classes dangereuses, Paris, Plon, 1958, p. 37 et p. $120-130$.

(51) Voir le titre de la Physiologie d'Ernest Bourget, op. cit.

(52) Selon l'Encyclopédie, un gamin est l'aide d'un souffleur de verre.

(53) Marie Théaulon de Lambert, Jules Gabriel de Lurieu, Le gamin de Londres, comé- point, il est facile de croiser les discours du philanthrope Bérenger de la Drôme devant les assemblées plénières de la Société pour le patronage des jeunes libérés du département de la Seine ${ }^{(47)}$ ou les descriptions de Frégier ${ }^{(48)}$ avec les propos lus dans les littératures pittoresques. En effet, l'archétype est construit alors que les observateurs sociaux et les "bienfaiteurs de l'humanité" découvrent le vagabondage juvénile, et les discours sur l'enfance populaire s'interpénètrent autant que les discours sur le crime de la Belle Époque étudiés par Dominique Kalifa. ${ }^{(49)}$ Louis Chevalier a relevé dans Les mystères de Paris et Les misérables, les emprunts à Frégier de Sue et Hugo. ${ }^{(50)}$ Nous pouvons aussi repérer dans Frégier les emprunts à Bérenger (Frégier est membre de la Société pour le patronage des jeunes libérés du département de la Seine) et, dans les rapports de Bérenger, les emprunts à la littérature pittoresque.

Le sentiment de cette errance juvénile est si fort que, même si les auteurs évoquent l'atelier et l'usine (où le gamin est initié au vice), même si la locution "galopin industriel" est utilisée comme synonyme de gamin, ${ }^{(51)}$ notre personnage n'est jamais représenté dans un lieu de travail. Il est toujours croqué dehors, sur une barricade, dans un lieu de spectacles ou de plaisirs (théâtre ou cabaret). Par réciproque, si des enfants sont représentés au travail, les légendes et sous-titres ne parlent pas de gamin, alors que le mot lui-même est issu de l'atelier. ${ }^{(52)}$

Last but not least, même si quelques auteurs se consacrent aux gamins de Londres ${ }^{(53)}$ ou de Lyon, ${ }^{(54)}$ le véritable gamin ne peut être que de Paris. « Il lui faut l'air de la Seine et les rumeurs du faubourg pour donner à son sang cette ardeur fiévreuse et vagabonde, pour allumer dans ses veines cette flamme intérieure qui l'anime et le consume. " ${ }^{(55)}$ L'évidence est telle, que les artistes cherchent rarement à souligner le fait en situant nos gamins dans un décor explicitement parisien. Les arrières-plans sont simplement urbains, sans que nous puissions désigner une ville précise.

\section{II.3 Les images contrastées du gamin de Paris}

$\mathrm{Au}$-delà de ces traits communs, le gamin a une face de lumière et une face d'ombre. S'il peut être présenté comme farceur, gouailleur, indiscipliné, mais bon, généreux, courageux, comme dans la pièce de Bayard 
et Vanderburch, ${ }^{(56)}$ il effraye aussi bien les frères Goncourt que l'inspecteur des prisons Moreau-Christophe, qui en font le symbole du vice. ${ }^{(57)}$ En réalité, dans la masse des textes qui lui sont consacrés, les opinions négatives l'emportent largement et, pour la majorité de "la classe qui écrit", le gamin appartient indiscutablement "aux classes dangereuses". Dès 1831, Auguste Barbier, auteur de Iambes et poèmes, transforme les petits patriotes de A. de Sainte en voyous :

«La race de Paris, c'est le pâle voyou

Au corps chétif, au teint jaune comme un vieux sou ;

C'est l'enfant criard que l'on voit à toute heure

Paresseux et flânant, et loin de sa demeure

Battant les maigres chiens, ou le long des grands murs

Charbonnant en sifflant mille croquis impurs $;^{(58)}$

Cet enfant ne croit pas, il crache sur sa mère,

Le nom de ciel pour lui n'est qu'une farce amère ;

C'est le libertinage enfin en raccourci ;

Sur un front de quinze ans c'est le vice endurci.

$[\ldots]$

Ô race de Paris, race au cœur dépravé,

Race ardente à mouvoir du fer ou du pavé !

Mer, dont la grande voix fait trembler sur les trônes

Ainsi que des fiévreux tous les portes-couronnes!

Flot hardi qui trois jours s'en va battre les cieux,

Et qui retombe après, plat et silencieux ! ${ }^{(59)}$

La face sombre du gamin, sa légende noire, aurait pu être personnalisée par Tortillard. Fils, comme Gavroche, d'un aubergiste véreux, mais malingre et contrefait, cruel et même sadique, nous trouvons dans le personnage inventé par Eugène Sue bien des éléments mis en avant par les contempteurs des enfants des classes dangereuses. Mais l'auteur des Mystères de Paris n'a pas fait de lien entre le rejeton de Bras-Rouge et le type "gamin" pourtant désormais bien individualisé. Le mot gamin ne figure jamais dans l'ouvrage pour désigner Tortillard.

Dans l'iconographie, nous retrouvons les deux faces du gamin. Cependant, faute d'un inventaire exhaustif, nous ne pouvons pas affir- die-vaudeville en 3 actes, Porte-Saint-Martin, 1841, Paris, imp. Boulé, (s.d.), 29 p.

(54) Le gamin de Lyon, Bordeaux, imp. H. Grazay, 1843, n. p.

(55) Victor Fournel, op. cit., p. 357-358.

(56) Jean-FrançoisAlbert Bayard, Émile Vanderburch, Le gamin de Paris, comédie-vaudeville en 2 actes, Paris, Dubuisson, (s.d.). La pièce, dont le rôle-titre est tenu par Bouffé, est jouée au Gymnase (Bonne Nouvelle) plus de 300 fois.

(57) Voir encadré.

(58) Dans les textes plus favorables, le gamin dessine des poires sur les murs (la poire est la synecdoque caricaturale de Louis-Philippe). Voir, par exemple, Louis Huart, op. cit., p. 73. 
(59) Auguste Barbier, Iambes et poèmes, Paris, Paul Masgana, 1840, p. 94 et 96 . Ce poème, composé en octobre 1831, est cité par plusieurs auteurs, notamment par Ernest Bourget, op. cit., p. 32. mer que la tendresse d'un Gavarni ou d'un Charlet l'emporte sur la dureté d'un Travies (qui semble avoir illustré le poème de Barbier) ou d'un Markl, même si, dans le corpus que nous avons constitué, la lumière l'emporte sur l'ombre.

\section{IMAGES DU GAMIN DE PARIS}
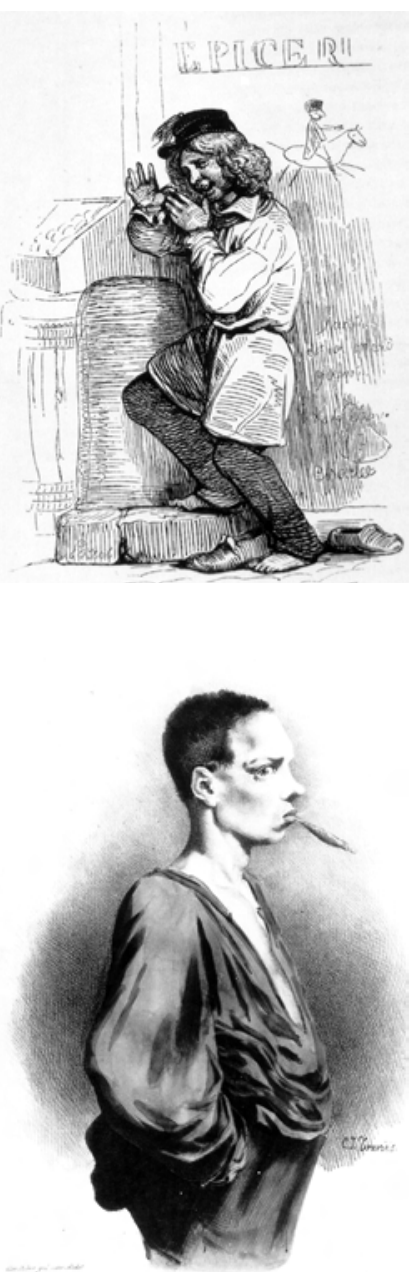

Fig. 10

Nicolas-Toussaint

Charlet, illustration pour "Le Gamin de Paris" de Jules Janin dans

Les Français peints par eux-mêmes, Paris, 1840. BHVP, cliché M. Basdevant.

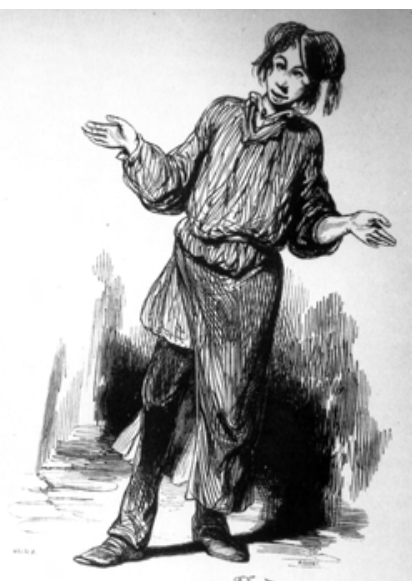

Fig. 11

Gavarni, illustration pour "Le Gamin de Paris" de Jules Janin dans

Fig. 12

Charles Joseph

Travies de Villiers, Titi le talocheur, galerie physionomique $n^{\circ} 26$.

Musée Carnavalet, PMVP,

cliché I. Andréani.

\section{Les Français peints} par eux-mêmes, Paris, 1840. BHVP, cliché M. Basdevant. 
Dans son versant voyou, le gamin est, comme l'écrit, entre autres, le philanthrope belge Ducpétiaux, tôt initié à tous les vices :

«L'apprenti se fait gamin à Paris, il devient polisson dans nos grandes villes. Il s'essaye à boire, à fumer ; il jure. Au sortir de l'atelier il est bruyant, querelleur ; ses jeux ne sont plus ceux des enfants de son âge. Il a dépouillé la robe d'innocence, et l'a jetée loin de lui. " ${ }^{(60)}$

La présence d'une pipe ou d'un cigare à un sou, qu'il fume " aux jours solennels ", ${ }^{(61)}$ nous renvoie vers la légende noire... D’ailleurs, Gavroche ne fume pas...

\section{II.4 L'héroïsation hugolienne et les images de Gavroche}

En 1862, après la publication des Misérables, le gamin se personnalise. Plus encore que Joseph, le premier rôle de la pièce jouée par Bouffé, Gavroche, généreux, drôle et courageux, est un héros positif. Remarquons tout de même, après Guy Rosa, que "Gavroche ne fonctionne pas seul mais en relation avec Petit-Gervais, qui est son passé historique, et avec Montparnasse, qui est son avenir personnel. " ${ }^{(62)}$ Si le cadet des Thénardier ne suit pas la pente fatale de Montparnasse, s'il reste de bout en bout un héros positif, c'est qu'il meurt sur la barricade. Nous n'analyserons pas ici la construction du personnage Gavroche. Nous retiendrons simplement que Victor Hugo n'innove pas vraiment. Il consacre un chapitre au gamin en général, où nous retrouvons, dans leurs acceptions positives, toutes les caractéristiques de l'archétype que nous avons énumérées, ${ }^{(63)}$ avant de nous présenter Gavroche comme « un petit garçon de onze à douze ans qui eût assez correctement réalisé cet idéal du gamin ébauché plus haut. " ${ }^{\left({ }^{64}\right)} \mathrm{Vu}$ le retentissement des Misérables, cet “idéal du gamin", idéal dans les deux sens du terme, tend à se substituer aux descriptions moins hérö̈ques. Autrement dit, après la publication des Misérables, " la profusion des images s'évanouit " ${ }^{\left({ }^{5}\right)}$ et, alors même que les appréhensions partiellement ou totalement négatives l'emportaient, survit essentiellement dans la mémoire collective l'image de cet enfant partageant le peu qu'il possède avec plus déshérité que lui, avant de mourir héroïquement sur une barricade au nom de la liberté. Le vicomte d'Haussonville a beau regretter, dans la Revue des deux mondes, ce manque de réalisme, la vision hugolienne s'impose :
(60) Édouard

Ducpétiaux, De la condition physique et morale des jeunes ouvriers et des moyens de l'améliorer, Bruxelles, Méline, Cans et compagnie, 1843 , p. 37.

(61) Victor Fournel, op. cit., p. 356.

(62) Guy Rosa, "Histoire sociale et roman de la misère: Les misérables de V. Hugo", Revue d'histoire du XIXème siècle, $\mathrm{n}^{\circ} 11,1995$, p. 101.

(63) Victor Hugo, Les misérables, (1862) 3ème partie, livre premier, "Paris étudié dans son atome", rééd. Paris, Robert Laffont, 1985, p. 457-470.

(64) Ibid., p. 470-471.

(65) Frédéric Chauvaud, art. cit., p. 25. 
(66) Nous retrouvons

le même rapprochement Hugo/Bouffé à

l'article gamin du Grand dictionnaire universel du XIXème siècle de Pierre Larousse. Mais là, la vision est positive.

(67) Vicomte d'Haussonville, "L'enfance à Paris", Revue des deux mondes, 1er juin 1878, p. 600 .

(68) Victor Hugo, Gavroche à six ans, dessin à l'encre de chine ; Gavroche rêveur, dessin à l'encre de chine ;

Gavroche à onze ans, dessin à l'encre de chine. Tous ces dessins sont conservés à la Maison de Victor Hugo.

(69) Georges d'Outremont, op. cit., p. 140.

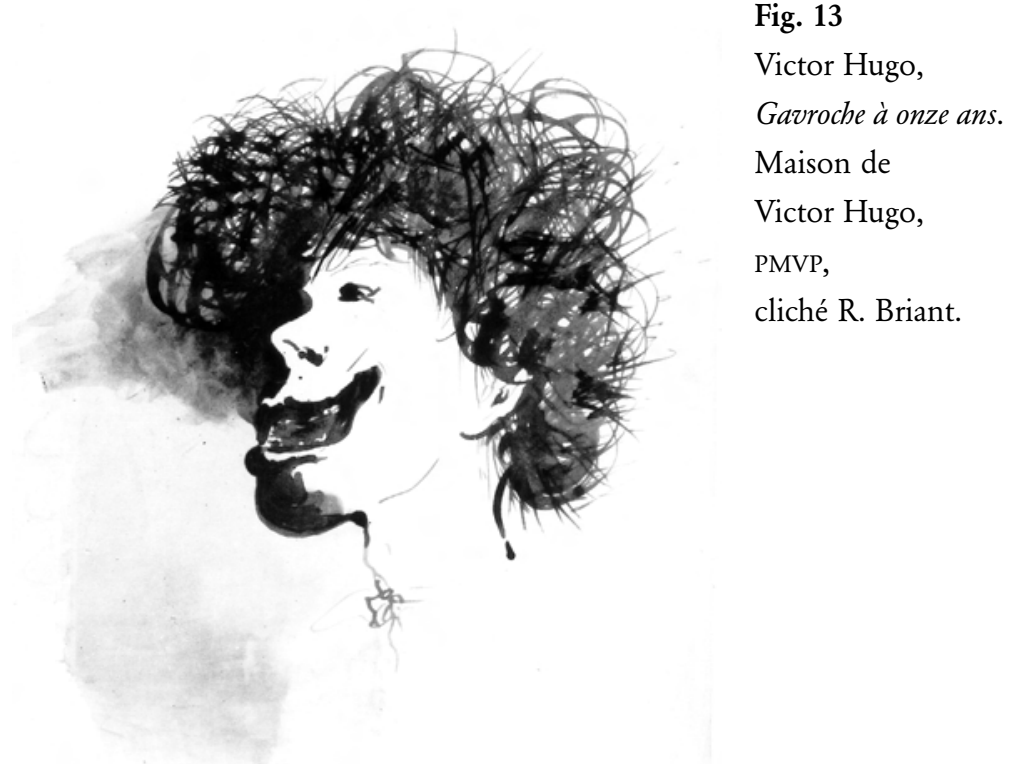

"Ce type bien connu devient, sur la scène ou dans la fiction, le gamin

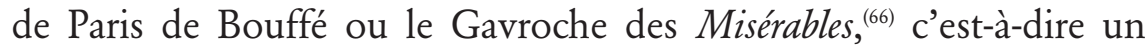
mélange attrayant d'esprit, de courage et de sensibilité. Dans la réalité, c'est un être profondément vicieux, familier depuis son jeune âge avec les dépravations les plus raffinées, un mélange de ruse, de couardise et, un jour donné, de férocité. » ${ }^{(67)}$

Dans cette "victoire" posthume de Gavroche, la figuration a-t-elle jouée un rôle ? Les représentations de Gavroche contribuent sûrement à fixer l'image de "l'idéal du gamin". En tout cas, le petit héros de l'auteur d'Hernani est très vite croqué. Victor Hugo lui-même en fait plusieurs portraits. ${ }^{(68)}$ Il semblerait que, pour faire son célèbre dessin à l'encre de Chine, Gavroche à onze ans [cf. figure 13], il ait suivi la description de Georges d'Outremont :

"Chaque fois que vous le rencontrerez, il aura l'air de vous narguer avec ses longs cheveux en désordre, son nez retroussé et sa bouche sardonique, l'air railleur et surtout insolent. ${ }^{(69)}$

Tous les illustrateurs des Misérables représentent Gavroche. Ils cher- 
chent à rendre l'esprit, la générosité et le courage du jeune garçon. En face du livre premier de la troisième partie, Paris étudié dans son atome, ils en dressent comme Émile Bayard le portrait en pied, en soulignant le côté farceur et ludique. Surtout, ils mettent Gavroche en situation dans les deux épisodes du roman où il montre sa générosité et son courage : le sauvetage des enfants de la Magnon, qui sont en fait ses frères, et l'insurrection. François Flameng, par exemple, nous offre un beau dessin de Gavroche et des deux "mioches". ${ }^{(70)}$

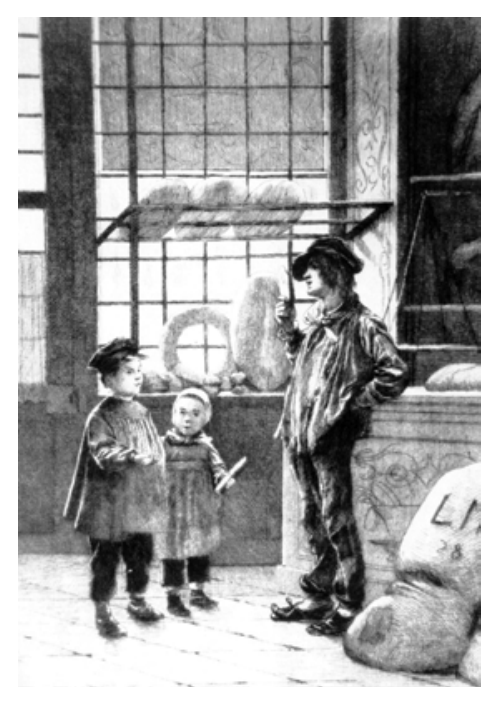

Fig. 14

François Flameng,

Gavroche.

Collection de

l'auteur,

cliché M. Basdevant.
(70) Dessin exécuté pour l'édition J. Hetzel A. Quantin, dite $n e$ varietur, de 1881.

(71) Eugène Hugues, éditeur (impr. J. Claye), s.d. (1879-1882), 5 vol., Grand in $8^{\circ}$. Dessins de Lix, E. Bayard, Brion, H. Scott, E. Morin, D. Vierge, Valnay, A. de Neuville, des Brosses,

J. P. Laurens, A. Marie,

E. Zier, E. Delacroix,

Vogel, Hersent,

Haenens, Benett.

(72) Brion réalise 200 dessins pour illustrer l'édition J. Hetzel et A. Lacroix de 1865. de porter sa montre à sa mère avant d'être fusillé... 
(73) Victor Hugo, L'année terrible, illustration de Léopold Flameng, Paris, Levy Frères, 1873.

(74) Pierre Larousse, Grand dictionnaire universel du XIXème siècle, cité par Luce Abélès, art. cit., p. 12. L'article du

"Larousse" est de 1872.

(75) Luce Abélès, art. cit., p. 12.

(76) Victor Hugo, op. cit., p. 461.

(77) Sur le colonialisme de Boussenard, voir Jean-Marc Proust, "Idéologie nationale et roman populaire sous la IIIème République”, Tapis-Franc. Revue du roman populaire, $\mathrm{n}^{\circ} 8$, 1997, p. 102-103.

(78) Louis Boussenard, Les aventures d'un gamin de Paris à travers l'Océanie, Paris, E. Dentu, 1883, $403 \mathrm{p}$.
- Piège grossier!

Et les soldats riaient avec leur officier,

Et les mourants mêlaient à ce rire leur râle ;

Mais le rire cessa, car soudain l'enfant pâle,

Brusquement reparu, fier comme Viala,

Vint s'adosser au mur et leur dit : Me voilà.

Dans l'édition illustrée du recueil, ${ }^{(73)}$ Léopold Flameng fixe la scène. [Cf. figure 15]

\section{Du gamin de Paris au gosse des rues}

\section{III.1 La fin du gamin}

Le gamin participe donc à la Commune, Victor Hugo lui-même en convient. Il est partout présent, dans l'iconographie, dans les archives militaires, dans l'Enquête parlementaire sur l'insurrection du 18 mars... Après le dernier grand soubresaut révolutionnaire du XIXème siècle, si l'on en croit Pierre Larousse, « le gamin admirablement dépeint par Victor Hugo se fait rare, grâce à la sévérité des lois sur le vagabondage ; on rencontre bien quelques pâles voyous ; mais le vrai gamin, le gavroche dont le romancier nous a

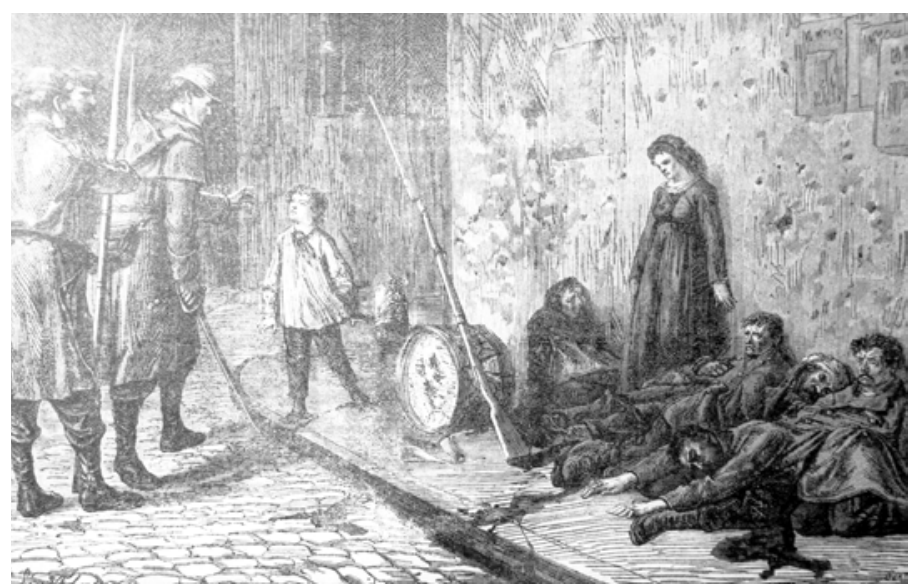

Fig. 15

Léopold Flameng, "Me voilà", L’année terrible, Paris, 1873. Collection de l'auteur, cliché M. Basdevant. 
laissé l'inimitable portrait est disparu ».(74) En fait, le gamin ne disparaît pas totalement, mais c'est sous une forme bien abâtardie qu'il survit.

D’abord le gamin devient un "agent publicitaire". La réclame utilise sa silhouette, "preuve que l'image reste ancrée dans l'imaginaire ", ${ }^{(75)}$ pour vanter les mérites de divers produits.

Ensuite, le gamin, dont Victor Hugo disait : "Pour eux, à deux lieues des barrières, il n'y a plus rien ", ${ }^{(76)}$ entreprend un tour du monde et se fait colonisateur. En 1879, dans le Journal des voyages, sous la "conduite" de Louis Boussenard, notre héros, trahissant la liberté qu'il avait chérie jusqu'à la mort (!), entreprend un périple autour du monde qui semble destiné à promouvoir la politique coloniale de la France. ${ }^{(77)}$ Le feuilleton sera repris en volumes et, dans les années 1880-1890, ce succédané de gavroche parcourt l'Océanie ${ }^{(78)}$ et l'Asie, ${ }^{(79)}$ en passant par l'Afrique. ${ }^{(80)}$

Dans le dernier quart du XIXème siècle, le gamin est devenu une image anecdotique ${ }^{(81)}$ et, s'il est encore représenté, il est très largement déréalisé. Comme le petit Savoyard ou la Bretonne en coiffe, il relève de plus en plus d'un folklore suranné. Un autre type le remplace : le gosse des rues, le môme de la Butte.

\section{III.2 Le gosse des rues}

Un véritable travail sur les représentations de l'enfance à la Belle Époque dépasse largement l'objet de cette étude. La production des Naudin, Steinlen, Willette ou Poulbot est trop riche pour être traitée en si peu de lignes. Nous voulons juste introduire quelques remarques sur les écarts et les continuités entre le gosse et le gamin.

\section{III.2.1 Un nouveau regard sur l'enfance}

Le début de la Troisième République correspond à un développement considérable de la notion d'intérêt de l'enfant. ${ }^{\left({ }^{(2)}\right)}$ Les lois scolaires, les lois réglementant le travail des enfants, les lois protectrices qui n'épargnent plus la "divine" " puissance paternelle, ${ }^{(83)}$ élaborées durant les premières décennies du nouveau régime, attestent, par leur nombre et plus encore par leur effectivité, de l'importance de ce souci de l'enfance. Dans ce contexte, les enquêtes se multiplient et la déviance juvé-

(79) Louis Boussenard, Les aventures d'un gamin de Paris au pays des tigres, Paris, Librairie illustrée, 1886, 343 p.

(80) Louis Boussenard, Les aventures d'un gamin de Paris au pays des lions, Paris, Librairie illustrée, 1886, 337 p.

(81) Expression de Luce Abélès, art. cit., p. 15 .

(82) Michelle Perrot, "La notion d'intérêt de l'enfant et son émergence au XIXème siècle”, Actes, cabier d'action juridique, nº 37, été 1982.

(83) Principalement la loi du 24 juillet 1889 relative à la protection des enfants maltraités ou moralement abandonnés (déchéance de la puissance paternelle), $J O$, 25 juillet 1889, p. 3653. 
(84) Notamment

Alfred Machard et sa série L'épopée au faubourg démarrée en 1912 avec Les cent gosses, suivis l'année suivante de Titine.

(85) Voir, par exemple, notre étude Jean-Jacques Yvorel, "Les enfants du ventre de Paris", à paraître.

(86) Émile Zola, Le ventre de Paris, (1873), Paris, Gallimard, 1960.

(87) Léon Frapié, La maternelle, Paris, Librairie universelle, 1905, 305 p.

(88) Jules Janin,

"Le gamin de Paris", in Les Français peints par eux-mêmes, Paris, Léon Curmer, 1840, tome II, p. 164.

(89) François Robichon, Poulbot, le pire des gosses, Paris, Hoïbeke, 1994, 111 p. nile est de plus en plus souvent corrélée au milieu socio-familial dans lequel évolue l'enfant. Jules Simon, auteur de L'ouvrier de huit ans, parle des "orphelins qui ont le malheur d'avoir des parents ", pour désigner les mineurs concernés par la loi de 1889.

La littérature, et notamment la littérature dite populiste, ${ }^{(84)}$ mais aussi le naturalisme ${ }^{(85)}$ incorporent ce nouveau regard sur l'enfant. Dès lors, le roman nous propose une vision plus "réaliste" de la vie enfantine. Prolongeant les enquêtes des spécialistes, les romanciers rendent compte du quotidien avec un souci du détail que le renvoi au type cohérent constitué par le gamin épargnait au narrateur précédent.

Jusque-là, seul Hugo avait détaillé avec un minimum de minutie les jeux des gamins. Généralement, les auteurs soulignaient le ludisme de ces petits parisiens et, en particulier, leur goût pour le "bouchon"»..., mais il fallait avoir recours au dictionnaire pour savoir en quoi ledit bouchon consistait. Zola, lui, décrit soigneusement les jeux de Muche ${ }^{(80)}$ et Frapié ceux des bambins de la maternelle. ${ }^{(87)}$ Les relations enfants/adultes sont désormais au cœur du dispositif narratif. Le gamin est sans famille ou il entretient avec elle des liens distendus ; le gosse en a une qui pèse de tout son poids et est présente jusqu'au milieu de ses jeux, qui sont souvent des mises en scène du quotidien familial. Enfin, les rapports de genre et la curiosité sexuelle ne sont plus occultés, alors même que le gosse est bien souvent plus jeune que le gamin (8-11 ans contre 12-15 ans). Par contre, si le gamin lisait fréquemment « quelques vieux fragments du Constitutionnel dans lequel il puise la haine des tyrans et l'amour du peuple " ${ }^{(88)}$ le gosse semble moins politisé.

Les crayons de Naudin, de Steinlen, de Willette et, bien sûr, de Poulbot ${ }^{(89)}$ traduisent graphiquement cette transformation du regard. Ils montrent aussi qu'entre Gavroche et les petits héros anonymes qu'ils croquent, notamment dans L'Assiette au beurre, la rupture n'est pas totale.

\section{III.2.2 Continuités et ruptures}

Le gosse partage avec le gamin plus d'un trait de caractère, et d'abord son extraction populaire qui se lit directement sur le vêtement. Il est aussi farceur, gouailleur et insolent, aussi irrespectueux des autorités, 
fussent-elles religieuses, mais beaucoup plus surveillé que son aîné.

On a pu écrire, à propos des petits poulbots, que "ce gosse des faubourgs vit, en toute innocence, sans ressentiment ni révolte, une situation sociale révoltante $"{ }^{(90)}$ Le propos est par trop absolu ; la révolte, du moins jusqu'en 1914, n'est pas absente chez les enfants qui naissent sous la plume de Francisque Poulbot. Il suffit de contempler la couverture qu'il réalise en novembre 1910 pour le journal libertaire Les Hommes du jour, ou la une de L'Humanité du 1er mai 1911, légendée "Aux Petits Prolétaires l'Avenir appartient ", également due à sa plume, ou encore le dessin qu'il exécute pour le supplément du Socialisme, journal de Jules Guesde, où l'un de ses gosses crie "Vive la Commune".(1)

Même si Victor Hugo note : "Quelquefois, dans ces tas de garçons, il y a des petites filles ", ${ }^{(92)}$ le gamin n'a pas vraiment de féminin. D’ailleurs,

(90) Les petits Poulbots :

Poulbot 1875-1946,

Musée départemental de l'éducation de Saint-

Ouen-l’Aumône, 1991.

(91) Le Socialisme, supplément du JournalRevue paraissant le samedi, premier numéro, 14 mars 1908, p. 1.

(92) Victor Hugo, Les misérables, op. cit., p. 461.

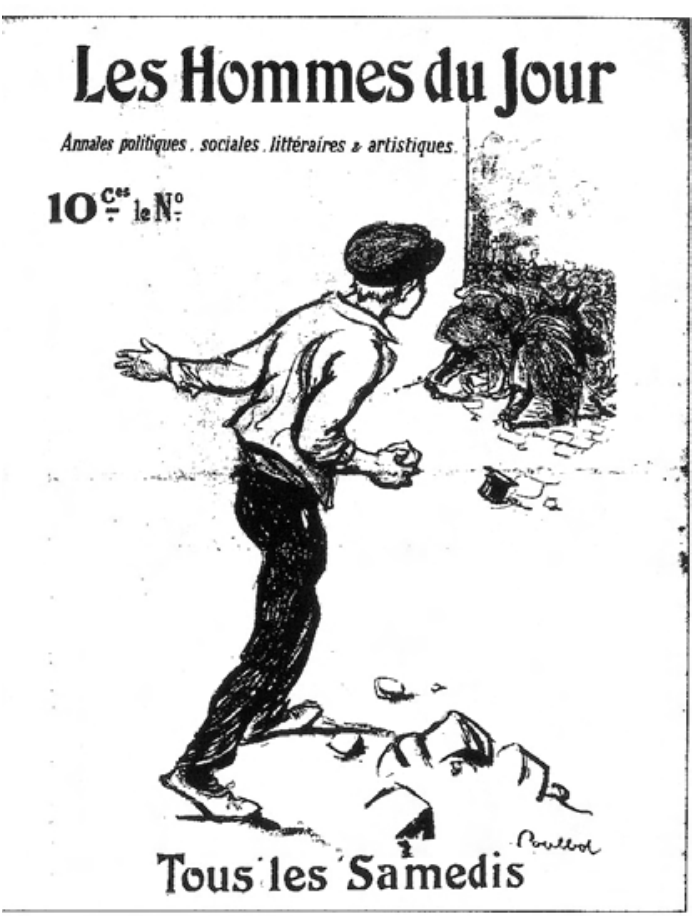

Fig. 16

Dessin de Poulbot pour le journal libertaire

Les Hommes du jour. Collection de l'auteur. 
(93) Pierre Larousse, Grand dictionnaire du XIXème siècle, article Gamin.

(94) « Il est le frère de la grisette : frère légitime ou illégitime qu'importe ». Jules Janin, op. cit., p. 161.

(95) Personnage de grisette dans Les mystères de Paris.

(96) L'expression est de Victor Hugo, op. cit., p. 463.

(97) Luce Abélès, art. cit., p. 15. le père des Misérables ne consacre que quatre lignes à la gamine sans même la nommer et le lexicographe soulignera, dix ans plus tard, la rareté de l'usage du féminin. ${ }^{(93)}$ Les filles du peuple ont généré un autre archétype, la grisette et, même si Jules Janin ${ }^{(94)}$ unit fraternellement Rigolette ${ }^{(95)}$ et Gavroche, le frère et la sœur ne se fréquentent pas. Pour le moins, aucun crayon, aucune plume, aucun pinceau n'a portraituré de gamines. Rien de tel avec les gosses. Le mot, qu'un changement de genre ne modifie pas, est usité pour les deux sexes et les illustrateurs ont dessiné autant de gosses en jupes que de gosses en pantalons. Surtout, la question des rapports entre hommes et femmes, garçons et filles, inexistante dans le monde de la gaminerie, ${ }^{(96)}$ est omniprésente dans l'univers des gosses. Elle surgit à travers les nombreux échos de la vie familiale qui transparaissent dans les jeux des enfants. Nos dessinateurs dénoncent notamment la violence des relations intrafamiliales. Souvent néo-malthusiens, ils critiquent le "lapinisme" de certains milieux populaires. Enfin, contrairement au gamin, le gosse n'est pas plus ou moins asexué. Il est plein d'une curiosité que Poulbot a traduite avec beaucoup d'humour dans Les Hommes du jour. Humour qui lui vaut les foudres du sénateur Bérenger, surnommé le Père la pudeur, qui essaie de le faire condamner pour outrage aux bonnes mœurs. [Cf. figure 17]

\section{Conclusion}

La nouvelle image de l'enfant pauvre de Paris est fabriquée à base de petites touches, de saynètes réalistes, de notations éparses qui relèvent "d'une esthétique du fragment ». ${ }^{(97)}$ Cet enfant est d'abord un enfant victime, même s'il n'est pas totalement sans défenses. L'archétype du gamin qui englobait l'enfance " classe dangereuse " et l'enfance " classe malheureuse » a éclaté. La Troisième République entend bien faire profiter du progrès l'enfance populaire. Elle a conçu pour atteindre ce but une formidable machine à intégrer et à acculturer : l'école républicaine gratuite, laïque et obligatoire. Parallèlement, elle s'efforce de mieux identifier et protéger l'enfant malheureux, comme le montre le vote de la loi du 24 juillet 1889 relative à la protection des enfants maltraités ou moralement abandonnés ou celle du 19 avril 1898 sur la répression des vio- 


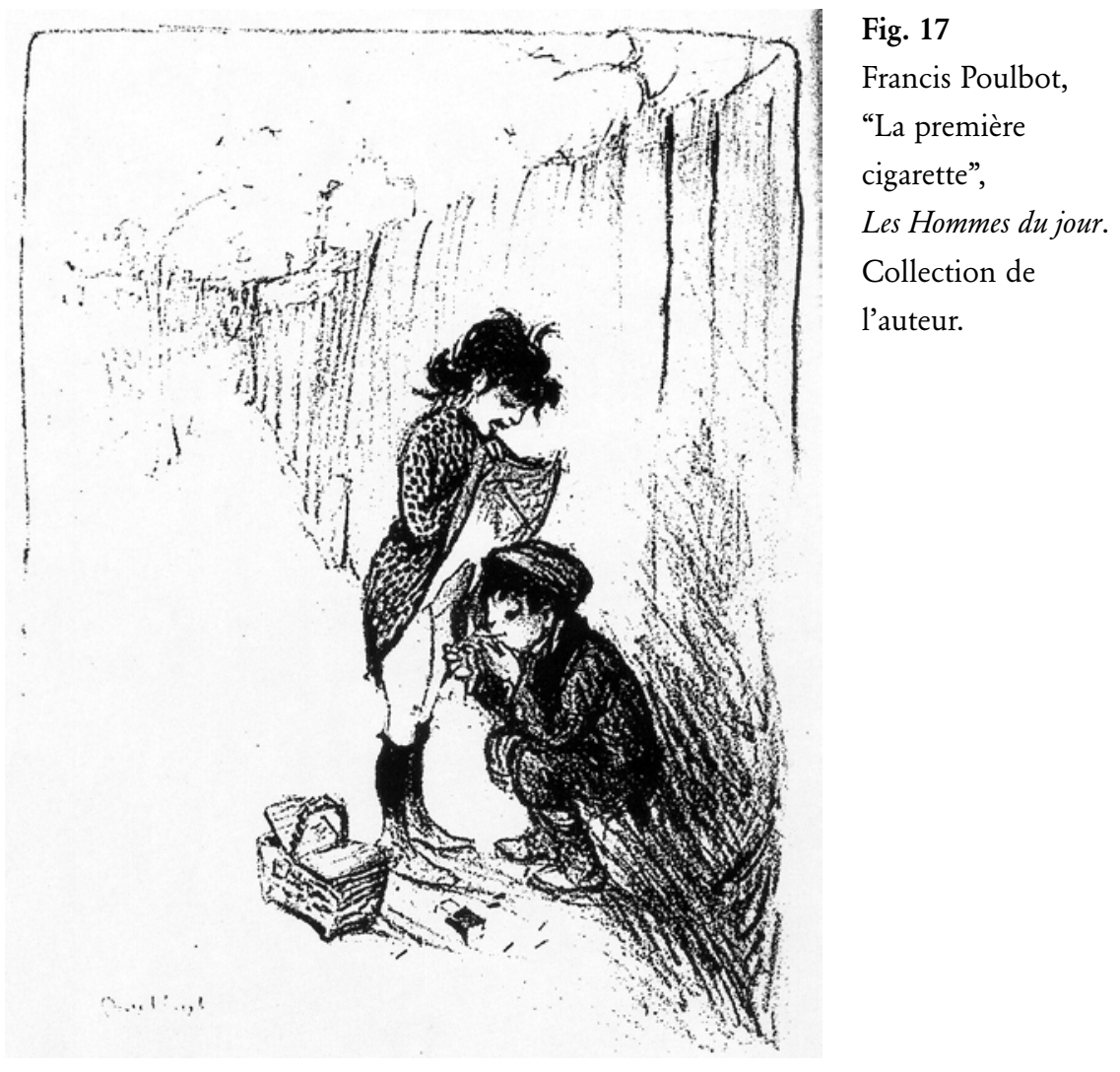

lences, voies de fait, actes de cruauté et attentats commis envers les enfants. Désormais, pour personnifier le "péril jeune", il faudra une figure plus irrémédiablement négative que le gamin ou que le pauvre gosse. C'est dans l'Apache, plus âgé, inéducable et inassimilable, que l'on retrouvera le symbole des classes dangereuses juvéniles. 


\section{Les deux visions du gamin de Paris}

\section{Côté ombre}

"L'enfant du peuple de Paris, le gamin de Paris, est à la fois un type et une exception ; l'enfant du peuple de Paris, du peuple de la dernière classe de la société, n'est pas enfant du peuple des communes rurales ; il appartient pour ainsi dire à une autre nation, à une autre race. C'est à proprement parler une individualité à part. Vous seriez surpris, Messieurs, de l'intelligence précoce d'un enfant de 11 ans de Paris. [...] C'est par l'intelligence qu'il brille, mais en même temps, c'est par le cœur qu'il pèche. Il pèche par le cœur parce que le plus souvent il appartient à une mère dont il a sucé les vices avec le lait, à un père habile dans l'art de vivre du bien d'autrui, à une famille dont les vertus domestiques sont le concubinage et la prostitution. Élevé à telle école, que voulez-vous que devienne ce malheureux ? [...] Placez cet enfant dans une colonie agricole et ce sera bientôt une colonie de petits bandits. Ce n'est pas les coloniser qu'il faut, mais les séquestrer, les isoler tous les uns des autres jusqu'au dernier. Tous sont infectés du même vice originel. On ne peut le détruire qu'en le neutralisant par l'emprisonnement individuel. »

Moreau-Christophe

[Débats du Congrès pénitentiaire de Bruxelles. Session de 1847, p. XVIII, cité par MarieSylvie Dupont-Bouchat, Éric Pierre, [dir.], Enfance et justice au XIXème siècle. Essais d'histoire comparée de la protection de l'enfance 1820-1914. France, Belgique, Pays-bas, Canada, Paris, PUF, 2001, p. 122.]

Le 20 mars 1866, les frères Goncourt croisent un gamin de douze ans. «Un petit bonhomme comme un petit nain ; une épaisse tignasse frisée sur la tête, dans laquelle à tout moment, il enfonce ses doigts, qui grattent ; des yeux effrontés ; avec un nez rouge dans une figure toute pâle, sortant de la loque et d'un foulard des Indes à ramages jaunes, qui lui fait une espèce de cache-nez ; des vêtements d'occa- 
sion, des grands souliers, blancs de boue de huit jours. " Après avoir reproduit la conversation entre le gamin et le commis de la librairie, puis entre le petit garçon et une petite fille de neuf ans, ils concluent : "Je n'ai jamais vu dans l'enfance une pareille fleur de fumier, une pareille coulée d'argot, une âme si flétrie, quelque chose produisant en vous une répulsion, qui va presque jusqu'à la peur - toutes les corruptions et toutes les canailleries de Paris dans un petit monstre de l'âge de la Première Communion, poussé au moral comme un sang où se seraient succédé trois générations de vérole; un de ces enfants où tout le mal, tout le vice d'une capitale de deux millions d'hommes est en effrayante miniature. "

[Edmond et Jules de Goncourt, Journal. Mémoires de la vie littéraire, II, 1866-1886, édition établie et annotée par Robert Ricatte, Paris, Robert Laffont, 1989, p. 14-15.]

\section{Côté lumière}

"Il est le frère de la grisette : frère légitime ou illégitime qu'importe. [...] Véritablement je ne serais pas étonné que le gamin de Paris et le moineau franc ne fussent les enfants de la même nichée. [...] C'est le souverain de cette ville. [...Soldat dans les armées de l'Empire c'était] la vivacité de l'esprit et le courage ; il était le bon mot de la bataille, la joie du bivouac, l'amour des cantinières, il riait et faisait rire. [...] Il est courageux, il est vaniteux, il est conteur, il est faquin, il est hardi et insolent comme un page ; son éloquence est infatigable, inépuisable ; un grand fond de philosophie, une patience à toute épreuve, une imprévoyance complète de toutes les choses humaines, un certain sentiment de la probité et du devoir qui ne l'abandonne jamais, tel est le fond du caractère de ce singulier personnage auquel on ne saurait rien comparer dans les autres pays de l'Europe. [...Il mange d'un cornet de pommes de terre puis] il se met à lire couramment l'enveloppe de son déjeuner, quelques vieux fragments du Constitutionnel de la veille, dans lequel il puise la haine des tyrans et l'amour du peuple. [...] Le gamin est un apprenti qui, même s'il se laisse distraire par quelques spectacles 
de la rue, aime bien son "bourgeois". Il est forgeron, c'est lui qui fait aller le soufflet ; il est peintre, c'est lui qui broie les couleurs ; il est architecte, c'est lui qui gâche le plâtre ; il est cordonnier, c'est lui qui passe le fil à la poix ; il est imprimeur, c'est lui qui lave les formes ; il est notaire royal, car c'est lui la cheville ouvrière des plus grandes affaires [puisqu'il porte les plis]. [...Il est] de toutes les révolutions. [...] Il est naturellement du parti le plus faible contre le plus fort, du parti sans armes contre le parti qui est armé. [...] Une fois dans l'émeute, il n'a plus qu'un désir, qu'une envie : c'est de forcer le palais des rois et de s'asseoir sur le trône du roi ; c'est de briser les portes des églises et de s'asseoir sur l'autel de Dieu ; c'est de défier en ricanant toutes les forces que les hommes respectent : il se figure que les révolutions ne sont faites que pour le faire rire, et son rire est tout voltairien. "

Jules Janin, "Le gamin de Paris", in Les Français peints par eux-mêmes, Paris, Léon Curmer, 1840, tome II, p. 161-166. 


\section{Les images de Gavroche dans les premières éditions des "Misérables"}

Ce tableau reprend toutes les représentations iconographiques de Gavroche dans les trois premières éditions illustrées des Misérables:

- Éd. J. Hetzel et A. Lacroix, 1865, 1 vol., in- $4^{\circ}$, illustrations de Brion.

- Éd. J. Hetzel et A. Quantin, Paris, 1881, 5 vol., in- $8^{\circ}$, (tomes V à IX de la section "Roman" de l'édition dite ne variatur, illustrations de François Flameng.

- Éd. Hugues, s.d., (1879-1882), 5 vol., grand in- $8^{\circ}$, illustrations de Lix, E. Bayard, Brion, H. Scott, E. Morin, D. Vierge, E. Delacroix, Vogel, Hersent, Haenens, Benett.

\begin{tabular}{|c|l|l|l|}
\hline AUTEUR & TITRE GRAVURE & \multicolumn{1}{|c|}{ CHAPITRE ILLUSTRÉ } & CONTENU DE L'IMAGE \\
\hline E. Bayard & Gavroche & $\begin{array}{l}\text { IIIème partie : Marius } \\
\text { Livre 1er : Paris étudié dans son atome } \\
\text { Chapitre XIII : Le petit Gavroche }\end{array}$ & $\begin{array}{l}\text { Portrait en pied } \\
\text { de Gavroche }\end{array}$ \\
\hline H. Vogel & $\begin{array}{c}\text { Gavroche } \\
\text { saisit la } \\
\text { bourse }\end{array}$ & $\begin{array}{l}\text { IVème partie : L'idylle rue Plumet et l'épopée } \\
\text { rue Saint-Denis } \\
\text { Livre 4ème : Secours d'en bas peut être secours } \\
\text { d'en haut } \\
\text { Chapitre II : La mère Plutarque n'est pas } \\
\text { embarrassée pour expliquer un phénomène }\end{array}$ & $\begin{array}{l}\text { Gavroche subtilise la } \\
\text { bourse du voyou } \\
\text { Montparnasse pour la } \\
\text { donner au pauvre } \\
\text { père Mabeuf et à la mère } \\
\text { Plutarque }\end{array}$ \\
\hline Neuville & $\begin{array}{c}\text { Le petit } \\
\text { Gavroche }\end{array}$ & $\begin{array}{l}\text { IVème partie : L'idylle rue Plumet et l'épopée } \\
\text { rue Saint-Denis } \\
\text { Livre 6ème : Le petit Gavroche } \\
\text { Frontispice du "livre 6" }\end{array}$ & $\begin{array}{l}\text { Gavroche dans l'éléphant } \\
\text { de la Bastille avec les deux } \\
\text { enfants Gillenormand/ } \\
\text { Magnon, qui sont en fait } \\
\text { ses frères }\end{array}$ \\
\hline
\end{tabular}




\begin{tabular}{|c|c|c|c|}
\hline AUTEUR & TITRE GRAVURE & CHAPITRE ILLUSTRÉ & CONTENU DE L'IMAGE \\
\hline Brion & $\begin{array}{l}\text { Gavroche } \\
\text { et les deux } \\
\text { enfants }\end{array}$ & $\begin{array}{l}\text { Ivème partie : L'idylle rue Plumet et l'épopée } \\
\text { rue Saint-Denis } \\
\text { Livre 6ème : Le petit Gavroche } \\
\text { Chapitre II : Où le petit Gavroche tire parti } \\
\text { de Napoléon le Grand }\end{array}$ & $\begin{array}{l}\text { Gavroche avec les deux } \\
\text { enfants Gillenormand/ } \\
\text { Magnon qu'il tient } \\
\text { par la main }\end{array}$ \\
\hline $\begin{array}{l}\text { François } \\
\text { Flameng }\end{array}$ & Gavroche & $\begin{array}{l}\text { IVème partie : L'idylle rue Plumet et l'épopée } \\
\text { rue Saint-Denis } \\
\text { Livre 6ème : Le petit Gavroche } \\
\text { Chapitre II : Où le petit Gavroche tire parti } \\
\text { de Napoléon le Grand }\end{array}$ & $\begin{array}{l}\text { Gavroche avec les deux } \\
\text { enfants Gillenormand/ } \\
\text { Magnon }\end{array}$ \\
\hline Brion & Mangez! & $\begin{array}{l}\text { IVème partie : L'idylle rue Plumet et l'épopée } \\
\text { rue Saint-Denis } \\
\text { Livre 6ème : Le petit Gavroche } \\
\text { Chapitre II : Où le petit Gavroche tire parti } \\
\text { de Napoléon le Grand }\end{array}$ & $\begin{array}{l}\text { Gavroche achète du pain } \\
\text { aux enfants Gillenormand/ } \\
\text { Magnon }\end{array}$ \\
\hline Brion & $\begin{array}{l}\text { Ascension } \\
\text { de l'éléphant }\end{array}$ & $\begin{array}{l}\text { Ivème partie : L'idylle rue Plumet et l'épopée } \\
\text { rue Saint-Denis } \\
\text { Livre 6ème : Le petit Gavroche } \\
\text { Chapitre II : Où le petit Gavroche tire parti } \\
\text { de Napoléon le Grand }\end{array}$ & $\begin{array}{l}\text { Gavroche aide les enfants } \\
\text { Gillenormand/Magnon à } \\
\text { pénétrer dans l'éléphant } \\
\text { de la Bastille }\end{array}$ \\
\hline Neuville & $\begin{array}{l}\text { L'évasion } \\
\text { de Thénardier }\end{array}$ & $\begin{array}{l}\text { IVème partie : L'idylle rue Plumet et l'épopée } \\
\text { rue Saint-Denis } \\
\text { Livre 6ème : Le petit Gavroche } \\
\text { Chapitre III : Les péripéties de l'évasion }\end{array}$ & $\begin{array}{l}\text { Gavroche regarde son père, } \\
\text { Thénardier, descendre } \\
\text { le long de la corde qu'il a } \\
\text { été fixer à la demande } \\
\text { de Montparnasse }\end{array}$ \\
\hline
\end{tabular}




\begin{tabular}{|c|c|c|c|}
\hline AUTEUR & TITRE GRAVURE & CHAPITRE ILLUSTRÉ & CONTENU DE L'IMAGE \\
\hline Lix & $\begin{array}{l}\text { L'atome } \\
\text { fraternise } \\
\text { avec } \\
\text { l'ouragan }\end{array}$ & $\begin{array}{l}\text { Ivème partie : L'idylle rue Plumet et l'épopée } \\
\text { rue Saint-Denis } \\
\text { Livre } 11 \text { ème : L'atome fraternise avec l'ouragan } \\
\text { Frontispice du livre } 11\end{array}$ & $\begin{array}{l}\text { Gavroche, un pistolet } \\
\text { à la main est en tête de } \\
\text { la manifestation } \\
\text { avec Enjolras et Mabeuf }\end{array}$ \\
\hline Brion & $\begin{array}{c}\text { Le pistolet } \\
\text { chipé }\end{array}$ & $\begin{array}{l}\text { Ivème partie : L'idylle rue Plumet et l'épopée } \\
\text { rue Saint-Denis } \\
\text { Livre 11ème : L'atome fraternise avec l'ouragan } \\
\text { Chapitre 1er : Quelques éclaircissements } \\
\text { sur les origines de la poésie de Gavroche... }\end{array}$ & $\begin{array}{l}\text { Gavroche s'approprie un vieux } \\
\text { pistolet d'arçon à la } \\
\text { devanture d'un bric-à-brac }\end{array}$ \\
\hline Brion & $\begin{array}{l}\text { Gavroche } \\
\text { en marche }\end{array}$ & $\begin{array}{l}\text { Ivème partie : L'idylle rue Plumet et l'épopée } \\
\text { rue Saint-Denis } \\
\text { Livre } 11 \text { ème : L'atome fraternise avec l'ouragan } \\
\text { Chapitre II : Gavroche en marche }\end{array}$ & $\begin{array}{l}\text { Gavroche fait un pied de nez } \\
\text { à quatre pauvres femmes } \\
\text { qui tiennent des propos } \\
\text { anti-révolutionnaires }\end{array}$ \\
\hline Brion & $\begin{array}{l}\text { C'est la souris } \\
\quad \text { qui a } \\
\text { pris le chat }\end{array}$ & $\begin{array}{l}\text { Ivème partie : L'idylle rue Plumet et l'épopée } \\
\text { rue Saint-Denis } \\
\text { Livre } 12 \text { ème : Corinthe } \\
\text { Chapitre VII : L'homme recruté rue des Billettes }\end{array}$ & $\begin{array}{l}\text { Gavroche contemple Jabert } \\
\text { ligoté par trois hommes } \\
\text { après qu'il eut indiqué sa } \\
\text { qualité de policier }\end{array}$ \\
\hline Lix & $\begin{array}{l}\text { Gavroche } \\
\text { et la charrette }\end{array}$ & $\begin{array}{l}\text { IVème partie : L'idylle rue Plumet et l'épopée } \\
\text { rue Saint-Denis } \\
\text { Livre } 15 \text { ème : La rue de l'homme armé } \\
\text { Chapitre IV : Les excès de zèle de Gavroche }\end{array}$ & $\begin{array}{l}\text { Gavroche s'empare } \\
\text { de la charrette d'un ivrogne } \\
\text { pour renforcer la barricade }\end{array}$ \\
\hline Brion & $\begin{array}{l}\text { Gavroche } \\
\text { fait sa récolte }\end{array}$ & $\begin{array}{l}\text { vème partie : Jean Valjean } \\
\text { Livre 1er : La guerre entre quatre murs } \\
\text { Chapitre XV : Gavroche dehors }\end{array}$ & $\begin{array}{l}\text { Gavroche sort devant } \\
\text { la barricade pour récolter } \\
\text { les cartouches des } \\
\text { gardes nationaux morts }\end{array}$ \\
\hline
\end{tabular}




\begin{tabular}{|l|l|l|l|}
\hline \multicolumn{1}{|c|}{ AUTEUR } & TITRE GRAVURE & \multicolumn{1}{|c|}{ CHAPITRE ILLUSTRÉ } & \multicolumn{1}{c|}{ CONTENU DE L'IMAGE } \\
\hline $\begin{array}{c}\text { François } \\
\text { Flameng }\end{array}$ & La barricade & $\begin{array}{l}\text { vème partie : Jean Valjean } \\
\text { Livre 1er : La guerre entre quatre murs } \\
\text { Chapitre XV : Gavroche dehors }\end{array}$ & $\begin{array}{l}\text { Plan large de Gavroche, } \\
\text { touché par une première } \\
\text { balle, qui élève } \\
\text { ses deux bras en l'air }\end{array}$ \\
\hline Brion & $\begin{array}{c}\text { La mort } \\
d e \text { Gavroche }\end{array}$ & $\begin{array}{l}\text { Lème partie : Jean Valjean } 1 \mathrm{er}: \text { La guerre entre quatre murs } \\
\text { Chapitre XV : Gavroche dehors }\end{array}$ & $\begin{array}{l}\text { Gros plan de Gavroche, } \\
\text { touché par une première } \\
\text { balle, qui élève } \\
\text { ses deux bras en l'air }\end{array}$ \\
\hline
\end{tabular}

